UMR 5824

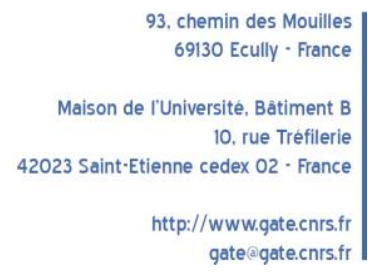

WP 1823 - October 2018

\title{
Heterogeneity, Rigidity and Convergence of Labor Markets in the Euro Area
}

Jocelyn Maillard

\begin{abstract}
:
This paper investigates the welfare consequences of labor market convergence reforms for a large range of calibrations in a two-country monetary union DSGE model with search and matching frictions. The model features trade in consumption and investment goods, price stickiness, firing costs and is calibrated to reflect the structural asymmetries of flexible and rigid countries of the Euro Area in terms of size and labor market variables. Across steady states, convergence brings welfare gains for the rigid country and welfare losses for the flexible country in most situations. The higher the flexibility induced by the convergence, the higher the gains for the rigid country and the lower the losses for the flexible country. Taking into account the transition path brings results that are qualitatively similar, but have a lower magnitude in terms of welfare gains/losses. Indeed, wage bargaining has a short-term negative impact on the rigid country and a short-term positive impact on the flexible country. As such, I conclude that convergence in labor markets can lead to substantial welfare gains in a monetary union, but only if the implementation is carefully designed.
\end{abstract}

\section{Keywords:}

Unemployment, Monetary Union, Labor Market Reform

JEL codes:

E32, F41, F45, J64

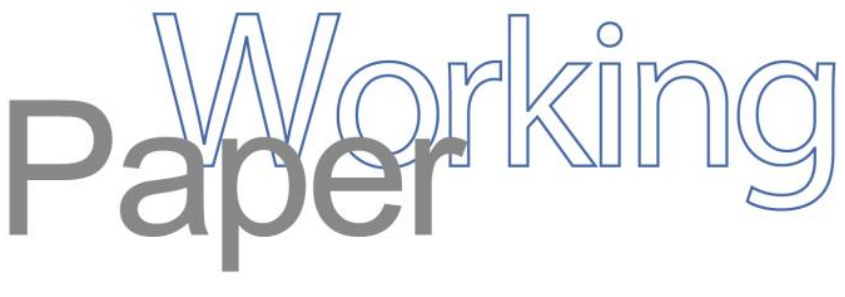




\title{
Heterogeneity, Rigidity and Convergence of Labor Markets in the Euro Area*
}

\author{
Jocelyn Maillard ${ }^{\dagger}$
}

February, 2018

\begin{abstract}
This paper investigates the welfare consequences of labor market convergence reforms for a large range of calibrations in a two-country monetary union DSGE model with search and matching frictions. The model features trade in consumption and investment goods, price stickiness, firing costs and is calibrated to reflect the structural asymmetries of flexible and rigid countries of the Euro Area in terms of size and labor market variables. Across steady states, convergence brings welfare gains for the rigid country and welfare losses for the flexible country in most situations. The higher the flexibility induced by the convergence, the higher the gains for the rigid country and the lower the losses for the flexible country. Taking into account the transition path brings results that are qualitatively similar, but have a lower magnitude in terms of welfare gains/losses. Indeed, wage bargaining has a short-term negative impact on the rigid country and a short-term positive impact on the flexible country. As such, I conclude that convergence in labor markets can lead to substantial welfare gains in a monetary union, but only if the implementation is carefully designed.
\end{abstract}

Keywords: Unemployment, Monetary Union, Labor Market Reform

JEL Classification: E32, F41, F45, J64

\footnotetext{
*I am grateful to Aurélien Eyquem for his helpful supervision. I thank Julien Albertini, Valentin Jouvanceau and Francesco Zanetti as well as participants at the Doctoriales Macrofi in Bordeaux and at the International Conference of the Society for Computational Economics in Milan for their comments and technical help.

${ }^{\dagger}$ Univ Lyon, Université Lumière Lyon 2, GATE UMR 5824. 93, Chemin des Mouilles, F-69130 Ecully, France; e-mail: maillard@gate.cnrs.fr.
} 


\section{Introduction}

The Eurozone is a monetary union of nineteen countries with heterogeneous structural characteristics. Unlike optimal currency areas, labor mobility is extremely limited and fiscal transfers are absent. ${ }^{1}$ The loss of monetary sovereignty by the countries of the Euro Area combined with the lack of cooperation and risk-sharing mechanisms to deal with asymmetric shocks has led the EMU to experience great difficulties to face the Great Recession. Relying on several economic indicators, the Euro Area appears in worse shape ten years after the crisis than it was just before. For instance, as Figure 1 indicates, the unemployment rate was at $10 \%$ of the active population in 2016, that is $33 \%$ higher than in 2007. Besides, most of the other OECD countries had a much lower unemployment rate in 2016 than the Eurozone (it was only higher in Turkey). Finding means to cope efficiently with asymmetric shocks, or shocks that spread asymmetrically is thus of great importance for the Euro Area.

Figure 1: Unemployment rate in OECD countries

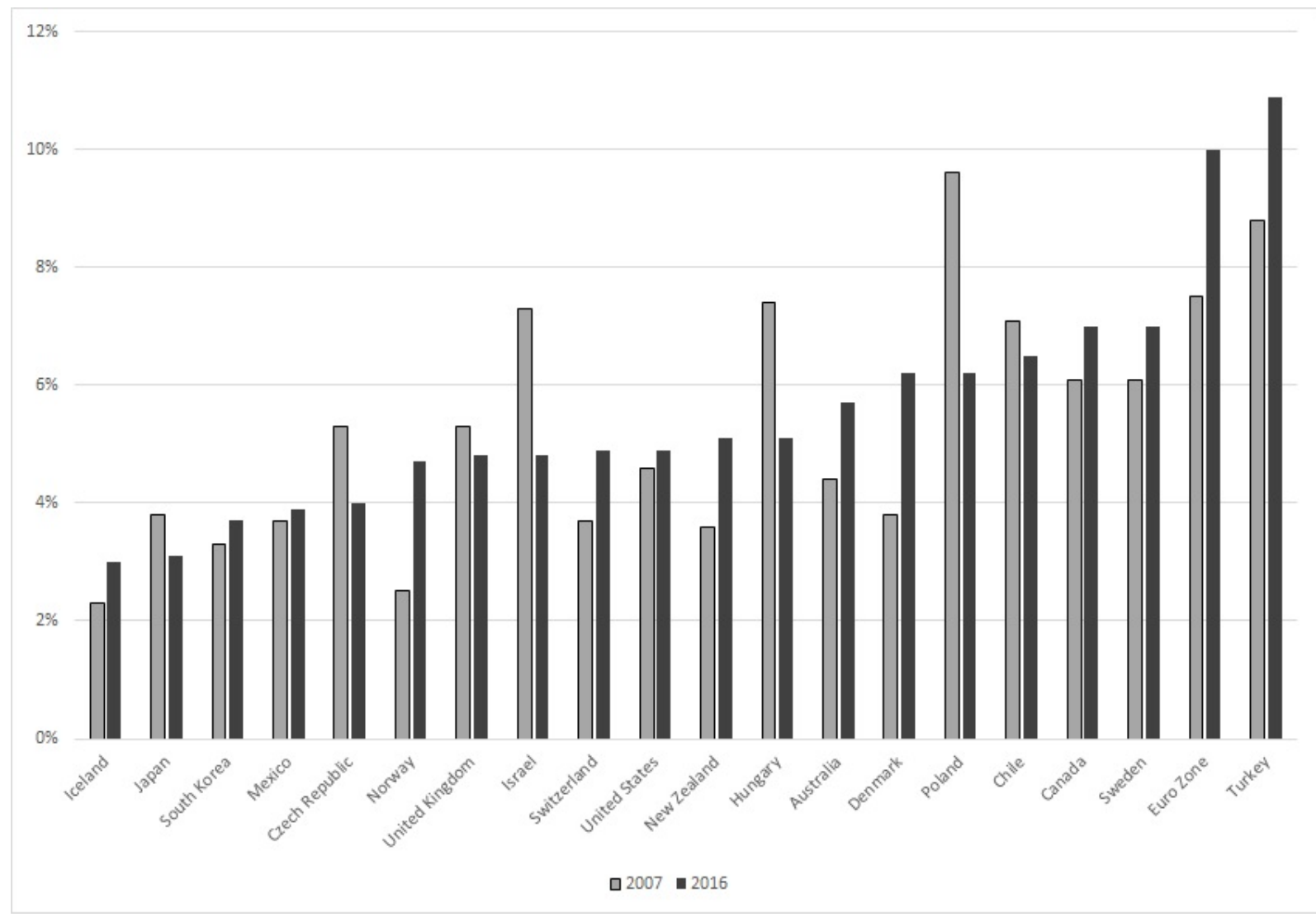

In this respect, I investigate the welfare consequences of labor market convergence reforms in a two-country monetary union model with search and matching frictions, where countries are asymmetric in terms of labor market variables. Indeed, Eurozone countries display important

\footnotetext{
${ }^{1}$ See Mundell (1961) or McKinnon (1963).
} 
labor market differences, especially in terms of labor market transition probabilities and unemployment insurance schemes. For instance, most countries have a net unemployment benefit replacement rate between $50 \%$ and $70 \%$ but there are huge differences between Malta, that has a net replacement rate of $20 \%$, and Portugal, where the replacement rate is at $92 \%$. Moreover, the duration period of eligibility ranges from 28 weeks in Slovenia to an unlimited period in Belgium (Esser et al., 2013). Countries in the Euro Area can also be divided according to the flexibility of their labor markets, that results from legislative choices. In flexible countries as Germany, the Netherlands or Ireland, firms make quicker and more efficient adjustments of their workforces. Employees have more flexible working time arrangements, the legislation protecting regular workers is close to the one protecting temporary workers and voluntary part-time work is higher. Moreover, overtime hours are more often observable and transition from temporary to permanent employment is higher (see Nardo and Rossetti (2013)). Differences in terms of labor market flexibility is considered by many authors as the main reason explaining the strong heterogeneity in terms of unemployment rate in the Eurozone, lower flexibility leading to higher unemployment levels. Figure 2 shows the large heterogeneity in cross-country unemployment rate in 2016. Flexible countries as Germany, Austria or the Netherlands experience low unemployment rates while rigid countries as Greece or Spain feature high unemployment rates.

Figure 2: Unemployment rate in the Eurozone in 2016

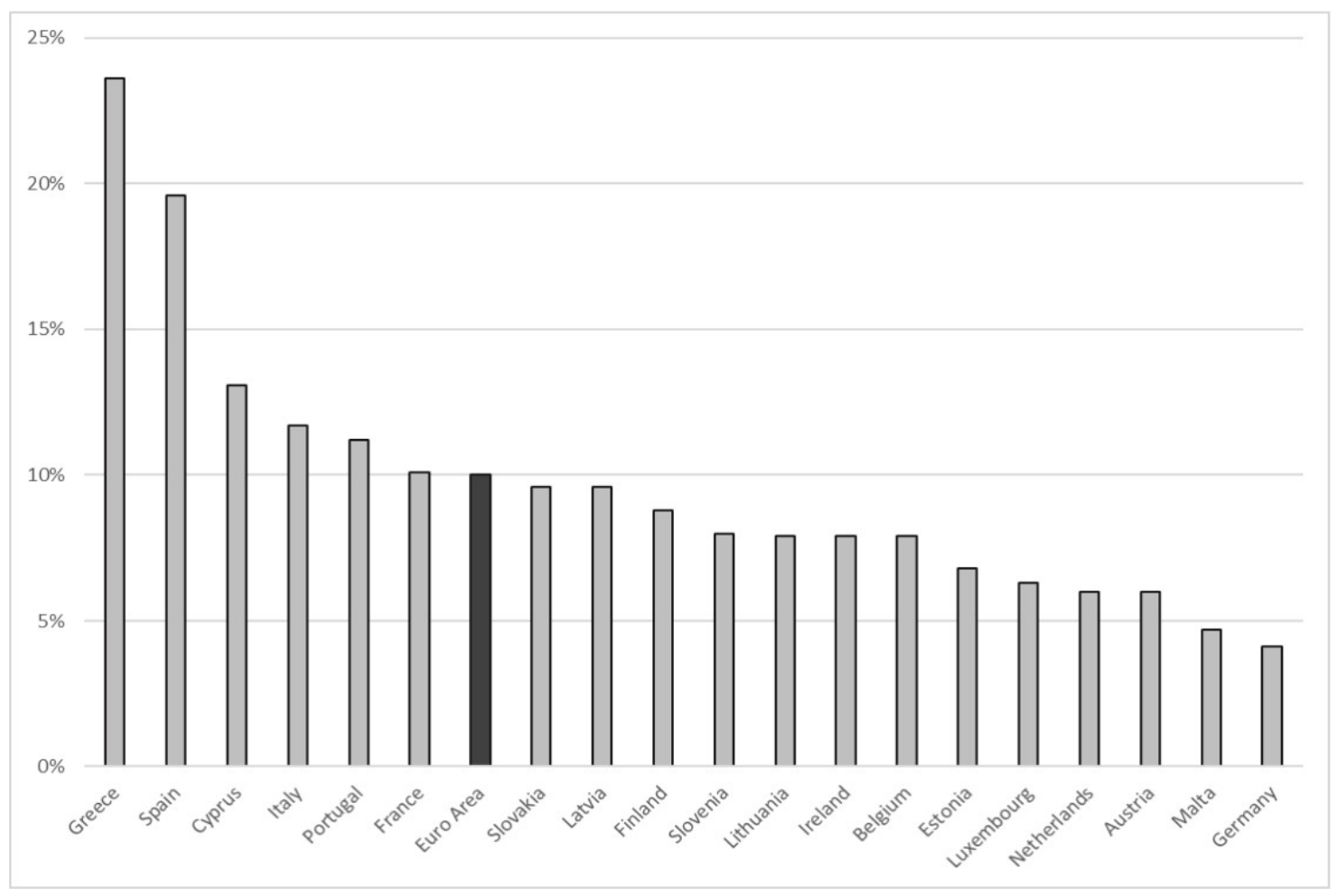

My two-coutry DSGE model features sticky prices, trade in consumption and investment goods, and home bias as in Pappa and Vassilatos (2007). Labor markets are frictional in the tradi- 
tion of Pissarides (1979), Mortensen (1982) and Diamond (1982). Firing costs are added as in Zanetti (2011). The Home country is meant to gather the flexible countries of the EMU while the Foreign country resembles the rigid countries. I carefully calibrate the model using Euro Area data. Countries are asymmetric in size, home bias and most labor market variables. In particular, in the steady state, flexible countries have a lower unemployment rate and a lower net unemployment benefit replacement rate, as in the data. Fed with asymmetric productivity shocks, the model matches business cycle moments satisfactorily. I then use the model to investigate the effects of labor market convergence reforms: labor market variables become identical in both countries, at various levels of labor market flexibility. Two welfare comparison exercises are performed: a steady-state to steady-state welfare comparison, where structural and stabilization gains are computed, and a welfare analysis based on the full transition path from heterogeneous to homogeneous labor markets.

The steady-state to steady-state comparison shows that labor-market convergence within the Euro Area brings structural welfare gains for the Foreign country and structural welfare losses for the Home country for any convergence calibration studied. Furthermore, the higher the after-convergence labor market flexibility, the higher the welfare gains (or the lower the losses). Indeed, labor market flexibility leads to more hiring, therefore more unemployed individuals are able to find a job. This lowers the unemployment rate and raises consumption, which has positive welfare consequences. The Monetary Union as a whole experiences welfare losses for a convergence towards a very rigid calibration. However, it experiences welfare gains after a convergence for a very large range of flexibility levels. Gains are large, even for the size-weighted average calibration. Indeed, in this case, when a shock occurs, the central bank can choose a monetary policy that better fits the situation of both countries. Besides, the higher the labormarket flexibility, the higher stabilization gains too. Indeed, when steady-state unemployment rates are lower, the volatility of unemployment rates and consumption aggregates is lower: higher labor market tightness stabilizes movements in matches, and in unemployment rates. It reduces the volatility of consumption aggregates and unemployment rates, and produces stabilization welfare gains. Those gains are quite large. The Home country experiences stabilization welfare gains for half of the levels of after-convergence labor market flexibility, and the Monetary Union as a whole for more than $80 \%$ of the levels of after-convergence flexibility.

The analysis of the full transition path does not strongly modify the insights resulting from the steady-state to steady-state comparison analysis. Again, in this case, the higher the level of the after-convergence flexibility of the labor markets, the higher the welfare gains or the lower the losses, both in the short and the long terms. The difference with the steady-state to steady-state analysis is that the magnitude of both gains and losses is lower. This comes from short-run adjustments that lower welfare in the (rigid) Foreign country and raise welfare in the (flexible) Home country. Indeed, individuals in the Foreign country understand that a higher future flexibility of their labor markets means a lower future bargaining power and lower future unemployment insurance benefits. Therefore, the equilibrium wage falls in period 1 of the transition, which has negative consequences on consumption and unemployment, and thus on 
welfare during the first few periods. Hence, welfare gains are lower for the Foreign country than they were in the steady-state to steady-state comparison. Foreign households even experience welfare losses in the short run for a transition towards a very rigid calibration of the labor market. The opposite mechanism occurs in the Home country: the increase of wages has positive effects on welfare which lowers the losses. Thus, for the Monetary Union as a whole, both losses from a convergence towards a rigid calibration and gains from a convergence towards a flexible calibration are lower. Welfare gains occur for a lower fraction of the range of convergence calibrations studied.

The remainder of the model is organized in the following way. Section 2 introduces the related literature. Section 3 presents the monetary-union model with search and matching frictions. Section 4 discusses the parametrization and looks at the fit of the model to the data in terms of business cycle moments. The main results are examined in Section 5, and Section 6 concludes.

\section{Related literature}

Labor market institutions of Eurozone countries have been studied by economists for nearly two decades. The first focus was the higher regulation and protection of workers that exists in Europe compared to Anglo-Saxon countries and their consequences mainly in terms of unemployment. Nickell (1997) tries to understand which types of employment protection legislation tend to increase unemployment. He considers that three policies should be avoided: high unemployment benefits without time limit or government pressure on the unemployed individuals to get a job; a large unionization with collectively bargained wages or an absence of coordination between unions or employers for the bargaining of wages; and the combination of a too high minimum wage for young workers and high payroll taxes. Blanchard and Wolfers (2000) show that it is the interaction of adverse shocks with the European labor market institutions that led to a higher unemployment in the European Union than in the US from the end of the 1970s. Individuals remain often a longer time unemployed in Europe due to the more generous benefits and the higher employment protection. They also explain that the heterogeneity in unemployment levels inside Europe are due to differences in terms of employment protection legislation between countries as the shocks that affect them are quite similar from a country to another.

Therefore, authors have built models to try to better explain those results and to look at the consequences of legislation that are less protective of workers and unemployed individuals. For example, Ljunqvist and Sargent (2008) obtain the same conclusion as Blanchard and Wolfers (2000): in tranquil times (as in the 1950s and 1960s) the higher employment protection led to a lower unemployment level in Europe than in the US. However, in a turbulent time (as from the late 1970s), it caused a consistently higher unemployment level in Europe. Indeed, high unemployment benefits are attractive for new unemployed individuals which lead them to ask for a high wage to drop the benefits. As such jobs are rare, they get somewhat discouraged and decrease their search of a new job. Blanchard and Giavazzi (2003) look, among other things, at the consequences of a decrease of the bargaining power of workers. They find that as it leads to 
a lower wage for workers, firms have more money available and therefore can hire more workers. Thus, the unemployment rate decreases in the long run. Focusing more precisely on Euro Area, Gomes et al. (2013) show that a decrease in labor market markup in Germany or Portugal would strongly increase output in each country and the rest of the monetary union. Furthermore, if the fall in labor market markup is made in cooperation between Eurozone countries, the effects would be stronger and more homogeneous between countries. Cacciatore et al. (2016) find that the adverse effects coming from a reduction of firing costs are much lower in a boom or in normal times than in a recession. On the contrary, output and employment increase more after a fall of unemployment benefits in the case of a recession than in normal times. Finally, Eggertsson et al. (2014) find that labor market reforms implemented when the interest rate is at the zero lower bound have very lasting adverse effects. They explain that in this case, at least in the short-run, a decrease of labor market markups would have a contractionary effect on the economy. Indeed, the real interest rate increases as agents expect the deflation to last, leading consumption to fall. Therefore, to avoid that the opposite impact to the expected one occurs, the timing of such reforms is crucial.

The heterogeneity of the labor markets inside the Euro Area was not a main concern at first. Dellas and Tavlas (2005) were among the firsts to look at the repercussion of an asymmetry in terms of wage rigidity in the Euro Area using a three-country model. They find that if countries are perfectly symmetrical, they all benefit from belonging to a monetary union and the higher their wage rigidities, the greater the welfare gains. But when countries are heterogeneous in terms of wage rigidities, only the most rigid countries gain from entering a monetary union. Belonging to a currency union brings welfare losses for the relatively more flexible countries. Later, Andersen and Seneca (2010) build a two-country model with size, shock and structural asymmetries to look at the consequences for the business cycle's properties as output and inflation volatility. The structural asymmetries include differences in terms of nominal rigidities and wage setting. They find very limited effects of those structural asymmetries at the union level but they conclude that they may play an important role at the country level. However, they do not include the search and matching framework which prevents them to look at more precise consequences of a decrease of labor market asymmetries. Abbritti and Mueller (2013) use this framework to study the consequences on inflation and unemployment differentials of asymmetries in terms of unemployment rigidities (employment protection legislation, hiring costs and matching technology) and wage rigidities (responsiveness of real wages). They find that the higher the asymmetries, the higher the volatility of inflation and unemployment differentials. Indeed, responses of both countries to shocks diverge with their labor market asymmetries. Differences in labor market institutions make the adjustments after shocks more difficult and longer. Kontogiannis (2015) uses a similar model to look at the optimal monetary policy in a monetary union when an asymmetry in terms of the degree of wage rigidity is present. He finds that such asymmetries lead to a welfare loss even for the optimal policy due to a higher volatility of the terms of trade. 


\section{Model}

The model consists of two countries in a Monetary Union: a Home country of size $n \in[0,1]$ representing flexible countries of the Euro Area and a Foreign country of size $(1-n)$ representing rigid countries. A central bank sets the nominal interest rate, while each government has an independent fiscal policy, that consists in setting the tax rates and the unemployment insurance (UI hereafter) benefit scheme. Each government buys local varieties of goods and finances expenditure through labor and capital income taxes, and one-period nominal bonds. Individuals have preferences over a bundle of domestic and foreign goods with home bias, supply labor and accumulate capital. Capital goods feature the same structure as consumption goods, with the same home bias. Firms in each country produce internationally-traded varieties of goods using labor and capital. They face sticky prices à $l a$ Rotemberg while labor markets are subject to search and matching frictions with endogenous separation and firing costs. The real wage is Nash-bargained as usual in this literature. Individuals have access to two types of bonds: local government one-period nominal bonds and international nominal bonds. Union-wide financial markets are incomplete and households face a portfolio adjustment cost that ensures the model's stationarity.

Countries are symmetric in structure but heterogeneous in terms of calibration. Therefore, this section only presents details of the model from the perspective of the Home country. If needed, foreign variables are denoted by an asterisk. Quantities are expressed per-capita. ${ }^{2}$

\subsection{Households}

In the Home country, there is a large family made of a continuum of $n$ individuals as in Merz (1995). ${ }^{3}$ A fraction $N_{t}=1-U_{t}$ is employed while the remaining portion $U_{t}$ is unemployed and searching for jobs. Family members are insured against unemployment risk: members pool their income to achieve the same level of individual consumption. Family members derive utility from consumption $C_{t}$ and from home production $h$ when unemployed. ${ }^{4}$ The family head thus maximizes its utility $u\left(C_{t}, U_{t}\right):^{5}$

$$
\max _{C_{t}} E_{t}\left[\sum_{t=0}^{\infty} \beta^{t} \frac{\left(C_{t}+h U_{t}\right)^{1-\gamma}}{1-\gamma}\right]
$$

subject to the budget constraint

$$
\begin{aligned}
& P_{t} C_{t}+P_{t} I_{t}+B_{t+1}+B_{M U, t+1}+P_{t} A C_{t} \\
& \quad=R_{t} B_{t}+R_{M U, t} B_{M U_{t}}+D_{i v_{t}}+\left(1-\tau_{t}^{W}\right)\left(\chi_{t} U_{t}+W_{t} N_{t}\right)+\left(1-\tau_{t}^{K}\right) R_{k, t} K_{t}+P_{t} \tau_{t}^{K} \delta K_{t}
\end{aligned}
$$

\footnotetext{
${ }^{2}$ Aggregate quantities can be easily obtained multiplying per capita quantities by each country's size.

${ }^{3}$ The Foreign family counts $1-n$ individuals.

${ }^{4} h$ is non-monetary. Its value, defined relatively to the country's steady-state wage, depends on labor market's conditions: the more flexible the labor market (the easier to find a job, the lower the steady-state unemployment rate), the lower $h$.

${ }^{5}$ See Albertini and Fairise (2013) for a similar utility function.
} 
and subject to the capital accumulation constraint

$$
K_{t+1}=(1-\delta) K_{t}+I_{t}
$$

In the utility function, $\gamma$ denotes the degree of relative risk aversion. ${ }^{6}$ On the LHS of the budget constraint, $P_{t}$ is the consumption price index, $K_{t+1}$ the stock of physical capital at the end of period $t, \delta$ the depreciation rate. The last term $A C_{t}=\frac{\Gamma}{2}\left(\frac{B_{M U, t+1}}{P_{t}}-\frac{\bar{B}_{M U}}{P}\right)^{2}$ denotes the portfolio adjustment costs paid on union-wide bonds, where $\bar{B}_{M U}$ is the steady-state level of foreign assets. ${ }^{7}$ On the RHS of the budget constraint, $B_{t}$ is the amount of one-period government nominal bonds paying $R_{t}$ between $t-1$ and $t$. Identically, $B_{M U, t}$ is the amount of union-wide bonds paying $R_{M U, t}$ between $t-1$ and $t$. Div is the profit of the monopolistic firms indexed in $i$ with $\operatorname{Div}_{t}=\frac{1}{n} \int_{0}^{n} D i v_{t}(i) d i, W_{t}$ is the average pre-tax nominal wage received by workers, $\tau_{t}^{W}$ is the tax rate on labor income, and $\chi_{t}$ is the pre-tax UI benefit. Finally, $R_{k, t}$ is the pre-tax rate of return on capital and $\tau_{t}^{K}$ is the capital income tax, that comes with a deduction on depreciated capital. First-order conditions with respect to $C_{t}, B_{t}$ and $B_{M U, t}$ imply:

$$
\begin{aligned}
\beta E_{t}\left\{\left(\frac{C_{t}+h U_{t}}{C_{t+1}+h U_{t+1}}\right)^{\gamma}\left[1+\left(1-\tau_{t+1}^{K}\right)\left(\frac{R_{k, t+1}}{P_{t+1}}-\delta\right)\right]\right\} & =1 \\
\beta E_{t}\left[\frac{P_{t}\left(C_{t}+h U_{t}\right)^{\gamma}}{P_{t+1}\left(C_{t+1}+h U_{t+1}\right)^{\gamma}} R_{t+1}\right] & =1 \\
\beta E_{t}\left[\frac{P_{t}\left(C_{t}+h U_{t}\right)^{\gamma}}{P_{t+1}\left(C_{t+1}+h U_{t+1}\right)^{\gamma}} \frac{R_{M U, t+1}}{\Gamma\left(\frac{B_{M U, t+1}}{P_{t}}-\frac{\bar{B}_{M U}}{P}\right)}\right] & =1
\end{aligned}
$$

Per-capita consumption, investment and adjustment costs are defined as Armington aggregators of Home and Foreign goods:

$$
\nu_{t}=\left[\alpha^{\frac{1}{\phi}}\left(\nu_{H, t}\right)^{\frac{\phi-1}{\phi}}+(1-\alpha)^{\frac{1}{\phi}}\left(\nu_{F, t}\right)^{\frac{\phi-1}{\phi}}\right]^{\frac{\phi}{\phi-1}}
$$

for $\nu=\{C, I, A C\}$. Variables $\nu_{H}$ and $\nu_{F}$ respectively stand for the quantities of Home and Foreign goods in the bundles, $\phi$ is the trade elasticity and $\alpha \in[0.5,1]$ expresses the preference for Home goods. ${ }^{8}$ Per-capita quantities of Home and Foreign goods are defined by the following bundles of varieties:

$$
\begin{aligned}
& \nu_{H, t}=\left[\left(\frac{1}{n}\right)^{\frac{1}{\psi}} \int_{0}^{n} \nu_{h, t}(i)^{\frac{\psi-1}{\psi}} d i\right]^{\frac{\psi}{\psi-1}} \\
& \nu_{F, t}=\left[\left(\frac{1}{1-n}\right)^{\frac{1}{\psi}} \int_{n}^{1} \nu_{f, t}(i)^{\frac{\psi-1}{\psi}} d i\right]^{\frac{\psi}{\psi-1}}
\end{aligned}
$$

\footnotetext{
${ }^{6}$ Since my quantitative exercises use either second-order approximations or non-linear solutions, certainty equivalence will not hold and $\gamma$ will be a key parameter.

${ }^{7}$ As shown by Schmitt-Grohé and Uribe (2003), these costs must be introduced to make the model stationary.

${ }^{8}$ Parameters $\alpha$ and $\alpha^{*}$ are defined according to the intra-EMU degree of openness of the monetary union $(1-\tilde{\alpha})$ in the following way $(1-\alpha)=(1-n)(1-\tilde{\alpha})$ and $\left(1-\alpha^{*}\right)=n(1-\tilde{\alpha})$.
} 
where $\nu_{h, t}(i)$ and $\nu_{f, t}(i)$ denote differentiated varieties of Home and Foreign goods, and $\psi$ is the elasticity of substitution among varieties. We assume that the law of one price holds. Since countries have a common currency, the Home consumption price index is:

$$
P_{t}=\left[\alpha\left(P_{H, t}\right)^{1-\phi}+(1-\alpha)\left(P_{F, t}\right)^{1-\phi}\right]^{\frac{1}{1-\phi}}
$$

where $P_{H, t}$ and $P_{F, t}$ are given by

$$
\begin{aligned}
P_{H, t} & =\left[\left(\frac{1}{n}\right) \int_{0}^{n} P_{h, t}(i)^{1-\psi} d i\right]^{\frac{1}{1-\psi}} \\
P_{F, t} & =\left[\left(\frac{1}{1-n}\right) \int_{n}^{1} P_{f, t}(i)^{1-\psi} d i\right]^{\frac{1}{1-\psi}}
\end{aligned}
$$

where $P_{h, t}(i)$ and $P_{f, t}(i)$ are respectively the price of Home and Foreign varieties. Optimization yields the following variety demands:

$$
\begin{aligned}
\nu_{h, t}(i) & =\frac{\alpha}{n}\left(\frac{P_{H, t}}{P_{t}}\right)^{-\phi}\left(\frac{P_{h, t}(i)}{P_{H, t}}\right)^{-\psi}\left(n \nu_{t}\right) \\
\nu_{h, t}^{*}(i) & =\frac{1-\alpha^{*}}{n}\left(\frac{P_{H, t}}{P_{t}^{*}}\right)^{-\phi}\left(\frac{P_{h, t}(i)}{P_{H, t}}\right)^{-\psi}\left((1-n) \nu_{t}^{*}\right) \\
\nu_{f, t}(i) & =\frac{1-\alpha}{1-n}\left(\frac{P_{F, t}}{P_{t}}\right)^{-\phi}\left(\frac{P_{f, t}(i)}{P_{F, t}}\right)^{-\psi}\left(n \nu_{t}\right) \\
\nu_{f, t}^{*}(i) & =\frac{\alpha^{*}}{1-n}\left(\frac{P_{F, t}}{P_{t}^{*}}\right)^{-\phi}\left(\frac{P_{f, t}(i)}{P_{F, t}}\right)^{-\psi}\left((1-n) \nu_{t}^{*}\right)
\end{aligned}
$$

\subsection{Firms}

In the Home country, a continuum of monopolistic firms indexed by $n$ use labor and capital to produce a variety of a final good.

\subsubsection{The labor market}

The labor market is subject to search and matching frictions. ${ }^{9}$ Households are divided between employed and unemployed. I consider that labor is immobile across countries. At each period, a job faces an exogenous productivity disturbance $A_{t}$ and an idiosyncratic shock $a_{t}$. The exogenous productivity shock is defined such that: $A_{t}=A_{t-1}^{\eta} \bar{A}^{1-\eta} \epsilon_{A, t}$, with $\epsilon_{A, t}$ an iid shock. The idiosyncratic shock follows a uniform distribution on the interval $[0,1]$ with c.d.f. $G(\cdot)$. Employment in period $t$ is composed of new and old workers. New workers matched at the end of period $t-1$ become productive in the next period with idiosyncratic productivity $a^{N}$. Old workers are those who were previously matched and survived the separation process. At the beginning of each period, first, exogenous separations occur with a probability $\rho^{x}$. Then, for $\rho_{t}^{n}=G\left(\underline{a}_{t}\right)$ of the

\footnotetext{
${ }^{9}$ For this part of the model, I mostly follow the models in Thomas (2006) and Zanetti (2011) to which I add capital.
} 
remaining jobs, $a_{t}$ falls below the endogenous profitability threshold $\underline{a}_{t}$ and the job is destroyed. As a consequence, the firm fires the worker and has to pay a firing cost $F$. Therefore, total job-separation rate is expressed as $\rho_{t}=\rho^{x}+\left(1-\rho^{x}\right) \rho_{t}^{n}$. To sum up, the aggregate law of motion of employment is defined as:

$$
N_{t}=\left(1-\rho^{x}\right)\left(1-\rho_{t}^{n}\right) N_{t-1}+M_{t-1}
$$

where $N_{t}$ is the beginning-of-period employment and $M_{t}$ is the number of matches formed during period $t$. New matches are formed according to a standard Cobb-Douglas matching function:

$$
M_{t}=m\left(V_{t}\right)^{1-\mu}\left(U_{t}\right)^{\mu}
$$

where $V_{t}=\frac{1}{n} \int_{0}^{n} V_{t}(i) d i$ is the number of vacancies, $m$ captures the efficiency of the matching process, and $\mu \in[0,1]$ is the matching elasticity. Defining $\theta_{t}=V_{t} / U_{t}$ as labor market tightness from the firms' point of view, the job-filling rate is the ratio of the number of new matches over the number of vacancies:

$$
q\left(\theta_{t}\right) \equiv \frac{M_{t}}{V_{t}}=m \theta_{t}^{-\mu}
$$

and the job-finding rate is the ratio of total new hires over the number of unemployed individuals:

$$
p\left(\theta_{t}\right) \equiv \frac{M_{t}}{U_{t}}=m \theta_{t}^{1-\mu}
$$

\subsubsection{Firms' Production}

When a working relation gets productive, each firm produces units of final good using labor and capital according to the following technology function

$$
Y_{t}(i)=A_{t} a_{t}\left(K_{t}(i)\right)^{\zeta}\left(N_{t}(i)\right)^{1-\zeta}
$$

with $K_{t}(i)$ and $N_{t}(i)$ defined such that $K_{t}=\frac{1}{n} \int_{0}^{n} K_{t}(i) d i$ and $N_{t}=\frac{1}{n} \int_{0}^{n} N_{t}(i) d i$. Firms take into account the demands for local varieties expressed by individuals and governments when setting their prices $P_{h, t}(i)$. Their objective is to maximize the profits they rebate to the family through dividends:

$E_{s} \sum_{s=t}^{\infty} Q_{t+s}\left[\left(\frac{P_{h, t+s}(i)}{P_{H, t+s}}-\frac{R_{k, t+s}}{P_{H, t+s}} K_{t+s}(i)-\frac{W_{k, t+s}}{P_{H, t+s}} N_{t+s}(i)-\frac{\kappa_{p}}{2}\left[\frac{P_{h, t+s}(i)}{P_{h, t+s-1}(i)}-1\right]^{2}\right) Y_{t+s}(i)-\kappa_{v} V_{t+s}(i)\right]$

where $Q_{t+s}=\beta\left(\frac{C_{t}+h U_{t}}{C_{t+s}+h U_{t+s}}\right)^{\gamma}$ is the stochastic discount factor. In addition, $V_{t}(i)$ is the number of vacancies and $\kappa_{v}$ the unit cost of a vacancy. Finally, $\frac{\kappa_{p}}{2}\left[\frac{P_{h, t}(i)}{P_{h, t-1}(i)}-1\right]^{2} Y_{t}(i)$ are adjustment costs paid at each change of price (see Rotemberg (1982)), with $\kappa_{p}>0$ a measure of price stickiness. Then, I define the first-order condition on the stock of capital thanks to this expression 
of dividends and the definition of the marginal cost $M C$ - common to all firms - detailed below:

$$
\zeta M C_{t} Y_{t}(i)=\frac{R_{k, t}}{P_{H, t}} K_{t}(i)
$$

Further, the optimal choice of $P_{h, t}(i)$ maximizes the expected stream of dividends subject to: ${ }^{10}$

$$
\begin{aligned}
{\left[1-\frac{\kappa_{p}}{2}\left(\frac{P_{h, t}(i)}{P_{h, t-1}(i)}-1\right)^{2}\right] Y_{t}(i)=} & \left(\frac{P_{h, t}(i)}{P_{H, t}}\right)^{-\psi}\left[\alpha\left(\frac{P_{H, t}}{P_{t}}\right)^{-\phi}\left(C_{t}+I_{t}+A C_{t}\right)\right. \\
& \left.+\frac{1-n}{n}\left(1-\alpha^{*}\right)\left(\frac{P_{H, t}}{P_{t}^{*}}\right)^{-\phi}\left(C_{t}^{*}+I_{t}^{*}+A C_{t}^{*}\right)+G_{t}+\kappa_{v} V_{t}\right]
\end{aligned}
$$

As every firm sets the same new price in equilibrium, we have $P_{h, t}(i)=P_{H, t}$. This allows us to obtain the following New Keynesian Phillips curve, that determines the evolution of the producer price index inflation $\pi_{H, t}=\frac{P_{H, t}}{P_{H, t-1}}$ :

$$
(1-\psi)+\psi M C_{t}+E_{t} Q_{t} \kappa_{p}\left(\pi_{H, t+1}-1\right) \pi_{H, t+1} Y_{t+1} / Y_{t}=\kappa_{p}\left(\pi_{H, t}-1\right) \pi_{H, t}
$$

\subsubsection{Wage determination}

The wage is determined through a Nash-bargaining process that involves the values for each firm of a vacancy and of a filled job as well as the values for individuals of being employed and of being unemployed. An unemployed individual receives net unemployment benefits and the value of the home production. He finds a job with a probability $p\left(\theta_{t}\right)$. Thus, the present-discounted value of unemployment $\mathscr{U}_{t}$ is:

$$
\mathscr{U}_{t}=\left(1-\tau_{t}^{W}\right) \frac{P_{H, t}}{P_{t}} \frac{\chi_{t}}{P_{H, t}}+h+E_{t} Q_{t}\left[p\left(\theta_{t}\right) \mathscr{W}_{t+1}^{N}+\left[1-p\left(\theta_{t}\right)\right] \mathscr{U}_{t+1}\right]
$$

Workers earn a different real wage whether they are new hires $w_{t}^{N}=\frac{W_{t}^{N}}{P_{H, t}}$ or old matches $w_{t}\left(a_{t}\right)=$ $\frac{W_{t}\left(a_{t}\right)}{P_{H, t}}$. The present-discounted values of a new match $\mathscr{W}_{t}^{N}$ and an old match $\mathscr{W}_{t}\left(a_{t}\right)$ are defined as:

$$
\begin{aligned}
\mathscr{W}_{t}^{N} & =\left(1-\tau_{t}^{W}\right) \frac{P_{H, t}}{P_{t}} w_{t}^{N}+E_{t} Q_{t}\left[\left(1-\rho^{x}\right) \int_{\underline{a}_{t+1}}^{1} \mathscr{W}_{t+1}\left(a_{t+1}\right) d G\left(a_{t+1}\right)+\rho_{t+1} \mathscr{U}_{t+1}\right] \\
\mathscr{W}_{t}\left(a_{t}\right) & =\left(1-\tau_{t}^{W}\right) \frac{P_{H, t}}{P_{t}} w_{t}\left(a_{t}\right)+E_{t} Q_{t}\left[\left(1-\rho^{x}\right) \int_{\underline{a}_{t+1}}^{1} \mathscr{W}_{t+1}\left(a_{t+1}\right) d G\left(a_{t+1}\right)+\rho_{t+1} \mathscr{U}_{t+1}\right]
\end{aligned}
$$

When looking for workers, firms post vacancies at a unit cost $\kappa_{v}$. They get filled with a probability $q\left(\theta_{t}\right)$ for a gain $\mathscr{J}_{t+1}^{N}$. Hence, the present-discounted value of a vacancy $\mathscr{V}$ is:

$$
\mathscr{V}_{t}=-\kappa_{v}+E_{t} Q_{t}\left[q\left(\theta_{t}\right) \mathscr{J}_{t+1}^{N}+\left[1-q\left(\theta_{t}\right)\right] \mathscr{V}_{t+1}\right]
$$

\footnotetext{
${ }^{10}$ A similar expression holds for the Foreign firm.
} 
Finally, using the first-order derivative of Equation (22), price symmetry among firms and free entry, ${ }^{11}$ I obtain the present-discounted value of a new match $\mathscr{J}_{t}{ }^{N}$ and of an old match $\mathscr{J}_{t}\left(a_{t}\right)$ that are identical for all firms:

$$
\begin{aligned}
& \mathscr{J}_{t}\left(a_{t}\right)=(1-\zeta) M C_{t} A_{t} a_{t} K_{t}^{\zeta} N_{t}^{-\zeta}-w_{t}\left(a_{t}\right)+E_{t} Q_{t}\left(1-\rho^{x}\right)\left[\int_{\underline{a}_{t+1}}^{1} \mathscr{J}_{t+1}\left(a_{t+1}\right) d G\left(a_{t+1}\right)-G\left(\underline{a}_{t+1}\right) F\right] \\
& \mathscr{J}_{t}^{N}=(1-\zeta) M C_{t} A_{t} a^{N} K^{\zeta} N_{t}^{-\zeta}-w_{t}^{N}+E_{t} Q_{t}\left(1-\rho^{x}\right)\left[\int_{\underline{a}_{t+1}}^{1} \mathscr{J}_{t+1}\left(a_{t+1}\right) d G\left(a_{t+1}\right)-G\left(\underline{a}_{t+1}\right) F\right]
\end{aligned}
$$

This value corresponds to the marginal profit that the firm obtains from a filled job at period $t$ plus the continuation value. Following Mortensen and Pissarides (2003), a match is profitable from the point where $\mathscr{J}_{t}\left(\underline{a}_{t}\right)+F=0$, as otherwise the firm fires the worker and must pay the firing tax. As a consequence, using Equation (29) at the productivity level $\underline{a}_{t}$, I obtain the expression defining the marginal cost as the wage minus the firing cost and the usual continuation term divided by the marginal product of labor:

$$
M C_{t}=\frac{1}{(1-\zeta) A_{t} \underline{a}_{t} K^{\zeta} N_{t}^{-\zeta}}\left[w_{t}\left(\underline{a}_{t}\right)-F-E_{t} Q_{t}\left(1-\rho^{x}\right)\left(\int_{\underline{a}_{t+1}}^{1} \mathscr{J}_{t+1}\left(a_{t+1}\right) d G\left(a_{t+1}\right)-G\left(\underline{a}_{t+1}\right) F\right)\right]
$$

As it is common in the literature, the real wage is determined through a Nash-bargaining solution involving the maximization of total surplus. The latter is a geometric average of the surplus of workers and the one of firms, weighted by their relative bargaining power $\sigma \in[0 ; 1]$ :

$$
\begin{aligned}
w_{t}\left(a_{t}\right) & =\arg \max \left(\mathscr{W}_{t}\left(a_{t}\right)-\mathscr{U}_{t}\right)^{\sigma}\left(\mathscr{J}_{t}\left(a_{t}\right)+F\right)^{1-\sigma} \\
w_{t}^{N} & =\arg \max \left(\mathscr{W}_{t}^{N}-\mathscr{U}_{t}\right)^{\sigma}\left(\mathscr{J}_{t}^{N}\right)^{1-\sigma}
\end{aligned}
$$

The solutions imply respectively:

$$
\begin{aligned}
\sigma\left(1-\tau_{t}^{W}\right) \frac{P_{H, t}}{P_{t}}\left(\mathscr{J}_{t}\left(a_{t}\right)+F\right) & =(1-\sigma)\left(\mathscr{W}_{t}\left(a_{t}\right)-\mathscr{U}_{t}\right) \\
\sigma\left(1-\tau_{t}^{W}\right) \frac{P_{H, t}}{P_{t}} \mathscr{J}_{t}^{N} & =(1-\sigma)\left(\mathscr{W}_{t}^{N}-\mathscr{U}_{t}\right)
\end{aligned}
$$

After simplifications, we obtain the determination of the real wage for old and new workers:

$$
\begin{aligned}
& w_{t}\left(a_{t}\right)=\sigma\left[M C_{t}(1-\zeta) K_{t}^{\zeta} N_{t}^{-\zeta} A_{t} a_{t}+\theta_{t} \kappa+\left(1-E_{t} Q_{t}\left(1-\rho^{x}\right)\right) F\right]+(1-\sigma)\left(\frac{\chi_{t}}{P_{H, t}}+\frac{h_{t}}{1-\tau_{t}^{W}} \frac{P_{t}}{P_{H, t}}\right) \\
& w_{t}^{N}=\sigma\left[M C_{t}(1-\zeta) K_{t}^{\zeta} N_{t}^{-\zeta} A_{t} a^{N}+\theta_{t} \kappa-E_{t} Q_{t}\left(1-\rho^{x}\right) F\right]+(1-\sigma)\left(\frac{\chi_{t}}{P_{H, t}}+\frac{h_{t}}{1-\tau_{t}^{W}} \frac{P_{t}}{P_{H, t}}\right)
\end{aligned}
$$

As usual, the real wage settles somewhere between the marginal productivity of labor plus the rent of a position filled - the upper bound - and the outside option for workers - the lower bound - that depends on UI benefits and the home production term. Wages differ by the compensation

\footnotetext{
${ }^{11}$ Free entry implies that $\mathscr{V}=0$
} 
$\sigma F$ for the savings on firing costs that only old matches receive.

Substituting Equation (36) into (29), and Equation (37) into (30), I obtain new expressions for the surplus for firms of an old and a new matches:

$$
\begin{gathered}
\mathscr{J}_{t}\left(a_{t}\right)+F=(1-\sigma)\left[(1-\zeta) M C_{t} A_{t} a_{t} K^{\zeta} N_{t}^{-\zeta}-\frac{\chi_{t}}{P_{H, t}}-\frac{h_{t}}{1-\tau_{t}^{W}} \frac{P_{t}}{P_{H, t}}+\left(1-E_{t} Q_{t}\left(1-\rho^{x}\right) F\right]\right. \\
-\sigma \theta_{t} \kappa+E_{t} Q_{t}\left(1-\rho^{x}\right)\left[\int_{\underline{a}_{t+1}}^{1}\left(\mathscr{J}_{t+1}\left(a_{t+1}\right)+F\right) d G\left(a_{t+1}\right)\right] \\
\mathscr{J}_{t}^{N}=(1-\sigma)\left[(1-\zeta) M C_{t} A_{t} a^{N} K^{\zeta} N_{t}^{-\zeta}-\frac{\chi_{t}}{P_{H, t}}-\frac{h_{t}}{1-\tau_{t}^{W}} \frac{P_{t}}{P_{H, t}}-E_{t} Q_{t}\left(1-\rho^{x}\right) F\right] \\
-\sigma \theta_{t} \kappa+E_{t} Q_{t}\left(1-\rho^{x}\right)\left[\int_{\underline{a}_{t+1}}^{1}\left(\mathscr{J}_{t+1}\left(a_{t+1}\right)+F\right) d G\left(a_{t+1}\right)\right]
\end{gathered}
$$

Then, using the fact that $\mathscr{J}_{t}\left(\underline{a}_{t}\right)+F=0$, I can write:

$$
\begin{aligned}
\mathscr{J}_{t}\left(a_{t}\right)+F & =\mathscr{J}_{t}\left(a_{t}\right)+F-\left(\mathscr{J}_{t}\left(\underline{a}_{t}\right)+F\right)=(1-\sigma)(1-\zeta) M C_{t} K_{t}^{\zeta} N_{t}^{-\zeta} A_{t}\left(a_{t}-\underline{a}_{t}\right) \\
\mathscr{J}_{t}^{N} & =\mathscr{J}_{t}^{N}-\left(\mathscr{J}_{t}\left(\underline{a}_{t}\right)+F\right)=(1-\sigma)\left[(1-\zeta) M C_{t} K_{t}^{\zeta} N_{t}^{-\zeta} A_{t}\left(a^{N}-\underline{a}_{t}\right)-F\right]
\end{aligned}
$$

Thanks to Equation(41), I obtain the job creation condition:

$$
\frac{\kappa}{q\left(\theta_{t}\right)}=(1-\sigma) E_{t} Q_{t}\left[(1-\zeta) M C_{t+1} K_{t+1}^{\zeta} N_{t+1}^{-\zeta} A_{t+1}\left(a^{N}-\underline{a}_{t+1}\right)-F\right]
$$

Finally, using Equation(40), I get the job destruction condition:

$$
\begin{aligned}
M C_{t}(1-\zeta) & K_{t}^{\zeta} A_{t} \underline{a}_{t}+\left(1-E_{t} Q_{t}\left(1-\rho^{x}\right)\right) F-\frac{\chi_{t}}{P_{H, t}}-\frac{P_{t}}{P_{H, t}} \frac{h_{t}}{1-\tau_{t}^{W}}-\frac{\sigma}{1-\sigma} \theta_{t} \kappa \\
& +E_{t} Q_{t}\left(1-\rho^{x}\right) M C_{t+1}(1-\zeta) K_{t+1}^{\zeta} N_{t+1}^{-\zeta} A_{t+1} \int_{\underline{a}_{t+1}}^{1}\left(a_{t+1}-\underline{a}_{t+1}\right) d G\left(a_{t+1}\right)=0
\end{aligned}
$$

\subsection{Governments}

Let's assume for simplicity purposes that firing costs are payed by firms to the government. Government expenditure and UI benefits are funded through taxes on capital and labor, firing costs

and public debt. The Home government consumes only local goods and government bond markets are fully segmented, i.e. purchased nationally. Therefore, the government has the following budget constraint, expressed in real terms:

$$
G_{t}+\left(1-\tau_{t}^{W}\right) \frac{\chi_{t}}{P_{H, t}} U_{t}+R_{t} \frac{B_{t}}{P_{H, t}}=\left(\frac{R_{k, t}}{P_{H, t}}-\frac{P_{t}}{P_{H, t}} \delta\right) K_{t} \tau_{t}^{K}+\frac{W_{t}}{P_{H, t}} N_{t} \tau_{t}^{W}+\frac{B_{t+1}}{P_{H, t}}+\omega_{t}^{O} N_{t} G\left(\underline{a}_{t}\right) F
$$


where $G_{t}$ is government expenditure ${ }^{12}$ and $\omega_{t}^{O}=\left(1-\rho_{t}\right) N_{t-1} / N_{t}$ is the weight of old matches. ${ }^{13}$ As the government issues nominal debt, it needs a feedback rule in order to produce stationary dynamics. I assume that government spending follows a simple feedback rule:

$$
G_{t}=s_{g} \bar{Y}-\phi^{b}\left(B_{t}-\bar{B}\right)
$$

where $s_{g}$ is the steady-state share of government spending in GDP, $\phi^{b}$ determines the speed of debt stabilization, and $\bar{B}$ is the steady-state level of debts.

\subsection{Central Bank}

I define the union-wide inflation rate $\pi^{M U}$ as a geometric weighted average of the Home CPI $\pi=P_{t} / P_{t-1}$ and the Foreign CPI $\pi^{*}=P_{t}^{*} / P_{t-1}^{*}$ :

$$
\pi_{t}^{M U}=\pi_{t}^{n}\left(\pi_{t}^{*}\right)^{1-n}
$$

The Central Bank has control over the nominal interest rate of the union-wide bond $R_{M U}$. It is set according to the following Taylor-type rule, close to the actual European Central Bank objectives:

$$
\log \left(\frac{R_{M U, t}}{\bar{R}_{M U}}\right)=\rho_{i} \log \left(\frac{R_{M U, t-1}}{\bar{R}_{M U}}\right)+\phi_{i} \log \left(\frac{\pi_{t}^{M U}}{\bar{\pi}^{M U}}\right)
$$

where $\rho_{i}$ expresses the persistence of the interest rate and $\phi_{i}>1$ determines the strength of the response of $R_{M U, t}$ to the inflation gap.

\subsection{Equilibrium}

In a symmetric equilibrium, the per-capita wage is a weighted average of wages of old and new matches. Therefore, we have:

$$
w_{t}=\sigma\left[M C_{t}(1-\zeta) K_{t}^{\zeta} N_{t}^{-\zeta} A_{t} \tilde{a}_{t}+\theta_{t} \kappa+\left(\omega_{t}^{O}-E_{t} Q_{t}\left(1-\rho^{x}\right)\right) F\right]+(1-\sigma)\left(\frac{\chi_{t}}{P_{H, t}}+\frac{h_{t}}{1-\tau_{t}^{W}}\right)
$$

where $\tilde{a}=\omega_{t}^{O} H\left(a_{t}\right)+\left(1-\omega_{t}^{O}\right) a_{t}^{N}$ is the average idiosyncratic productivity for all jobs with $H\left(\underline{a}_{t}\right)=\int_{\underline{a}_{t}}^{1} a_{t} g\left(a_{t}\right) /\left(1-G\left(\underline{a}_{t}\right)\right) d a_{t}=E\left(a_{t} \mid a_{t}>\underline{a}_{t}\right)$ the average idiosyncratic productivity among continuing jobs. Furthermore, the per-capita production is $Y_{t}=A_{t} \tilde{a}_{t} K_{t}^{\zeta} N_{t}^{1-\zeta}$. Then, to close the model, we need to use the variety demand Equation (24) and its foreign counterpart,

\footnotetext{
${ }^{12}$ The latter are defined as:
}

$$
G_{t}=\left[\left(\frac{1}{n}\right)^{\frac{1}{\psi}} \int_{0}^{n}\left(G_{t}(\omega)\right)^{\frac{\psi-1}{\psi}} d \omega\right]^{\frac{\psi}{\psi-1}}
$$

The corresponding variety demands are therefore

$$
G_{t}(\omega)=\frac{1}{n}\left(\frac{P_{h, t}(\omega)}{P_{H, t}}\right)^{-\psi} G_{t}
$$

\footnotetext{
${ }^{13}$ Thus, the weight of new matches that will be of use below is $1-\omega_{t}^{O}$
} 
and aggregate over varieties to get:

$$
\begin{aligned}
&\left(1-\frac{\kappa_{p}}{2}\left(\pi_{H, t}-1\right)^{2}\right) Y_{t}=\alpha\left(\frac{P_{H, t}}{P_{t}}\right)^{-\phi}\left(C_{t}+I_{t}+A C_{t}\right) \\
&+ \frac{1-n}{n}\left(1-\alpha^{*}\right)\left(\frac{P_{H, t}}{P_{t}^{*}}\right)^{-\phi}\left(C_{t}^{*}+I_{t}^{*}+A C_{t}^{*}\right)+G_{t}+\kappa V_{t} \\
&\left(1-\frac{\kappa_{p}}{2}\left(\pi_{F, t}-1\right)^{2}\right) Y_{t}^{*}=\alpha^{*}\left(\frac{P_{F, t}}{P_{t}^{*}}\right)^{-\phi}\left(C_{t}^{*}+I_{t}^{*}+A C_{t}^{*}\right) \\
&+\frac{n}{1-n}(1-\alpha)\left(\frac{P_{F, t}}{P_{t}}\right)^{-\phi}\left(C+I+A C_{t}\right)+G_{t}^{*}+\kappa^{*} V_{t}^{*}
\end{aligned}
$$

The clearing condition on the union-wide bond market is

$$
n \frac{B_{M U, t}}{P_{t}}+R E R_{t}(1-n) \frac{B_{M U, t}^{*}}{P_{t}^{*}}=0
$$

where $R E R_{t}$ is the real exchange rate defined as $R E R_{t}=P_{t}^{*} / P_{t}$. Finally, aggregating all budget constraints yields the dynamics of foreign assets of the domestic economy:

$\frac{B_{M U, t+1}}{P_{t}}-R_{M U, t} \frac{B_{M U, t}}{P_{t}}=\frac{P_{H, t}}{P_{t}}\left[\left(1-M C_{t}-\frac{\kappa_{p}}{2}\left(\pi_{H, t}-1\right)^{2}\right) Y_{t}+w_{t} N_{t}+\frac{R_{k, t}}{P_{H, t}} K_{t}-G_{t}-\kappa_{t} V_{t}\right]-C_{t}-I_{t}-A C_{t}$

Finally, for future reference, I define the terms of trade as:

$$
T_{t}=\frac{P_{F, t}}{P_{H, t}}
$$

\section{Calibration, solution, and business cycle moments}

Size. The calibration is meant for the Home country to gather the main flexible countries of the Eurozone (Austria, Finland, Germany, Ireland and the Netherlands) and for the Foreign country to resemble the main rigid countries of the Eurozone (Belgium, France, Greece, Italy, Luxembourg, Portugal and Spain). ${ }^{14}$ The size of each country represents the labor force of each region of the Euro Area: the Home country has a size $n=0.41$.

Preferences, trade and openness. The period is a quarter, as our business cycle matching exercise will use quarterly data. Hence, $\beta$ is calibrated to 0.99 , which implies an annualized steady-state nominal interest rate of roughly $4 \%$. I have assumed that inflation rates have no trends, therefore $\bar{\pi}=\bar{\pi}^{*}=\bar{\pi}_{H}=\bar{\pi}_{F}^{*}=\bar{\pi}^{M U}=1$. Further, according to OECD data, both groups of countries have the same weighted average productivity. Therefore, I set $\bar{A}=\bar{A}^{*}=1$. Moreover, the value of $\bar{T}$ is undetermined in the steady state. I choose $\bar{T}=1$ to follow relative productivity levels. Risk aversion $\gamma$ is set at 2 as in Mayer et al. (2010) and many others. I choose the same value as in Schmitt-Grohé and Uribe (2003) concerning portfolio intermediation cost:

\footnotetext{
${ }^{14}$ See Appendix A for a description of the method to identify those two groups of countries.
} 
$\Gamma=0.0007$ to imply an annual interest rate premium of $3 \%$. Based on intra-EMU trade openness data, the intra-EMU import share is $(1-\tilde{\alpha})=30 \%$. It implies $\alpha=0.823$ and $\alpha^{*}=0.877$. The value of the trade elasticity remains debated in the literature, with very different values used in the DSGE literature and the literature on international trade. I choose a low value of $\phi=2$ as in Obstfeld and Rogoff (2005).

Production. The depreciation rate of capital is $\delta=0.025$ to match a $10 \%$ yearly depreciation. The capital share is set to $\zeta=0.36$ which is a usual value in the literature. The elasticity of substitution between varieties $\psi$ is set to 6 as in Brückner and Pappa (2012) in order to have a gross steady-state markup of $20 \%$. I choose $\kappa_{p}=80$ which is a plausible value considering the price markup as indicated in Ireland (2001), Keen and Wang (2007), or Born and Pfeifer (2016) among others.

Labor market. I set the elasticity of the matching function to $\mu=0.5$ which belongs to the range of credible values as described in Petrongolo and Pissarides (2001). The calibration of the bargaining power of workers greatly differs from a paper to another. I set it to better match second-order moments of the unemployment rate and comply with the differences between countries that are shown in the data. ${ }^{15}$ I choose $\sigma=0.8$ and $\sigma^{*}=0.9$. I assume that new workers enter with an idiosyncratic productivity of 0.4 to better match the volatility of unemployment. I calculate the separation rates using the data from Hobijn and Sahin (2007). I obtain $\rho=0.032$ and $\rho^{*}=0.033$. Then, following Albertini and Fairise (2013), I choose exogenous separations to be twice more frequent than endogenous ones at the steady-state. Therefore, I get: $\bar{\rho}^{n}=0.0108$ and $\rho^{x}=0.0216$ for the home country and $\bar{\rho}^{n}=0.0111$ and $\rho^{x}=0.0222$ for the foreign country. Further, I set up the steady-state values of the job-finding rates in order to get specific steadystate values of the unemployment rate. I set it equal to the average unemployment rate value weighted by the labor force in both areas of the Eurozone between the second quarter of 1998 and the first quarter of 2017 . Those values are $\bar{U}=6.96 \%$ and $\bar{U}^{*}=11.17 \%$. To get them, I choose $\bar{p}(\theta)=0.4277$ and $\bar{p}(\theta)^{*}=0.2624$. I set the job-filling rate higher for the flexible country: $\bar{q}(\theta)=0.7$ and $\bar{q}(\theta)^{*}=0.6$. I use the data of Esser et al. (2013) to compute a labor force weighted average of the net UI benefit replacement rates. I obtain $\frac{\chi}{\bar{W}}=60 \%$ and $\frac{\chi^{*}}{\bar{W}^{*}}=65 \%$. To have those net UI benefit replacement rates, I need to choose the following values of home production: $h=0.1018$ and $h^{*}=0.1097$. Those values imply quite low values of vacancy costs: $\frac{\kappa_{v}}{W}=0.044$ and $\frac{\kappa_{v}^{*}}{\bar{W}^{*}}=0.007$. Finally, the firing costs are a lump sum set such that $\frac{F}{\bar{W}}=45 \%$ and $\frac{F^{*}}{\bar{W}^{*}}=65 \%$.

Policy. The shares of government consumption in GDP $s_{g}$ are set to 0.18 in both countries. Moreover, $\phi^{b}$ is set to 0.1 , which means that more than half of the deviation of debt to its steadystate value is closed in roughly two years. I follow Mayer et al. (2010) for the monetary rule by setting the persistence at $\rho_{i}=0.85$ and the response to inflation at $\phi_{i}=2$. The steady-state tax rates on capital income are computed using data from Trabandt and Uhlig (2013). I use

\footnotetext{
${ }^{15}$ The bargaining power of workers summarizes the union density, the union coverage, and the coordination in wage bargaining between unions and between employers. The three characteristics tend to be higher in rigid countries of the Euro Area (see Nickell (1997)).
} 
country-level tax rates to calculate GDP-weighted average tax rate for each zone. I find very close values for the tax rate on capital. I choose $\tau^{K}=\tau^{* K}=0.34$. Finally, I adjust the tax rates on labor income to obtain a steady-state debt-to-GDP ratio of $72 \%$ in country $\mathrm{H}$ and $82 \%$ in country F. These levels correspond to $\tau^{W}=0.35$ and $\tau^{* W}=0.38$.

Shocks. I set the persistence of productivity shocks at $\eta=\eta^{*}=0.9$ and their volatility at $\operatorname{std}\left(\epsilon_{a, t}\right)=\operatorname{std}\left(\epsilon_{a, t}^{*}\right)=0.9 \%$ to better match absolute volatility of output. Finally, the crosscountry correlation of shocks is 0.7 . Table 1 below summarizes my parameter values.

Table 1: Calibration for the baseline model

\begin{tabular}{|c|c|c|c|}
\hline Parameters & Symbol & Core & Periphery \\
\hline Discount factor & $\beta$ & & 0.99 \\
\hline Degree of risk aversion & $\gamma$ & & 2 \\
\hline Depreciation rate of capital & $\delta$ & & 0.025 \\
\hline Portfolio intermediation costs & $\Gamma$ & & 0.0007 \\
\hline Elasticity of substitution between varieties & $\psi$ & & 6 \\
\hline Trade elasticity & $\phi$ & & 2 \\
\hline Parameter of the production function & $\zeta$ & & 0.36 \\
\hline Persistence of the productivity shocks & $\eta$ & & 0.90 \\
\hline Rotemberg cost parameter & $\kappa_{p}$ & & 80 \\
\hline Match elasticity & $\mu$ & & 0.5 \\
\hline Share of government consumption & $v$ & & 0.18 \\
\hline Persistence of the interest rate & $\rho_{i}$ & & 0.85 \\
\hline Parameter associated with $\pi^{M U}$ & $\phi_{i}$ & & 2 \\
\hline Policy parameter & $\phi_{b}$ & & 0.1 \\
\hline Tax rate on capital & $\tau^{K}$ & & 0.34 \\
\hline Tax rate on labor & $\tau^{W}$ & 0.35 & 0.38 \\
\hline Country size & $n$ & 0.41 & 0.59 \\
\hline Home bias & $\alpha$ & 0.823 & 0.877 \\
\hline Vacancy cost & $\kappa_{v}$ & 0.044 & 0.007 \\
\hline Value of home production & $h$ & 0.1018 & 0.1097 \\
\hline Firing cost & $\frac{F}{\bar{W}}$ & 0.65 & 0.45 \\
\hline Bargaining power of workers & $\sigma$ & 0.8 & 0.9 \\
\hline Exogenous separation rate & $\rho^{x}$ & 0.0216 & 0.0222 \\
\hline Labor market variables & Symbol & Core & Periphery \\
\hline Steady-state unemployment rate & $\bar{U}$ & 0.0696 & 0.1117 \\
\hline Unemployment benefit replacement rate & $\frac{\chi}{\bar{W}}$ & 0.60 & 0.65 \\
\hline Steady-state job-finding rate & $\bar{p}(\theta)$ & 0.4277 & 0.2624 \\
\hline Steady-state job-filling rate & $\bar{q}(\theta)$ & 0.7 & 0.6 \\
\hline Steady-state total separation rate & $\bar{\rho}$ & 0.032 & 0.033 \\
\hline Steady-state endogenous separation rate & $\overline{\rho^{n}}$ & 0.0108 & 0.0111 \\
\hline
\end{tabular}

Solution and second-order moments. The model is solved using second-order perturbation 
methods. ${ }^{16}$ I first compare the implied second-order moments of important variables with those of the data to gauge the quality of the model. Empirical second-order moments were obtained using the OECD database. I use quarterly data from 1998Q2 to 2017Q1 for GDP, private consumption and investment, building GDP-weighted averages for each zone. Unemployment rates are labor force weighted average rates. The moments are computed on HP-filtered series taken in logs with a smoothing parameter of 1600 .

Table 2 shows that the moments of the model match fairly well those of the data. Although the volatility of consumption is lower in the model, relative standard deviations are well reproduced. Consumption and investment are strongly pro-cyclical both in the model and the data while unemployment is strongly countercyclical. The model reproduces strong cross-country correlations for all variables, although most of this cross-country correlation stems from the cross-country correlation of shocks. Finally, the large persistence observed in the data is relatively well replicated by the model, especially for private consumption and unemployment. Appendix B presents the Impulse Response Functions produced after technology shocks and provides more details on the transmission mechanisms that generate those second-order moments. Overall, the model reproduces most features of the European business cycle and is therefore a reliable representation of the economy of the Euro Area.

Table 2: Comparison between the model and the data of the second moments of specific variables

\begin{tabular}{|c|c|c|c|c|c|c|c|c|}
\hline \multirow{2}{*}{ Variable $Z$} & \multicolumn{2}{|c|}{$\sigma_{Z} / \sigma_{Y}$} & \multicolumn{2}{|c|}{$\operatorname{Corr}(Z ; Y)$} & \multicolumn{2}{|c|}{$\operatorname{Corr}\left(Z_{t} ; Z_{t-1}\right)$} & \multicolumn{2}{|c|}{$\operatorname{Corr}\left(Z ; Z^{*}\right)$} \\
\hline & Model & Data & Model & Data & Model & Data & Model & Data \\
\hline$Y$ & - & - & - & - & 0.77 & $(0.89)$ & \multirow[b]{2}{*}{0.67} & \multirow{2}{*}{$(0.91)$} \\
\hline$Y^{*}$ & - & - & - & - & 0.85 & $(0.90)$ & & \\
\hline$C$ & 0.28 & $(0.55)$ & 0.96 & $(0.81)$ & 0.81 & $(0.82)$ & \multirow{2}{*}{0.62} & \multirow{2}{*}{$(0.73)$} \\
\hline$C^{*}$ & 0.31 & $(0.92)$ & 0.98 & $(0.95)$ & 0.87 & $(0.88)$ & & \\
\hline$I$ & 4.69 & $(2.37)$ & 0.96 & $(0.85)$ & 0.75 & $(0.86)$ & \multirow{2}{*}{0.47} & \multirow{2}{*}{$(0.87)$} \\
\hline$I^{*}$ & 4.63 & $(2.61)$ & 0.97 & $(0.96)$ & 0.86 & $(0.91)$ & & \\
\hline$U$ & 5.23 & $(4.38)$ & -0.88 & $(-0.68)$ & 0.91 & $(0.92)$ & \multirow{2}{*}{0.75} & \multirow{2}{*}{$(0.66)$} \\
\hline$U^{*}$ & 5.75 & $(5.18)$ & -0.91 & $(-0.94)$ & 0.92 & $(0.93)$ & & \\
\hline
\end{tabular}

\section{Labor market convergence in the Euro Area}

My ultimate objective in this section is to investigate the steady-state and business cycle implications of labor market convergence within the Euro Area. I simply imagine that a piece of legislation is implemented in the Euro Area, making labor market institutions identical in both countries. Implementing this change of legislation in the DSGE model means that the Home and the Foreign countries have a new steady state where all labor market parameters and variables

\footnotetext{
${ }^{16}$ I use the Dynare setup (see Adjemian et al. (2011)).
} 
are identical. Therefore, I design a new calibration with identical bargaining power of workers, separation rates, job-filling rates, job-finding rates, matching efficiency, firing costs, vacancy costs, tax rates on labor and home production parameters. This implies especially identical net unemployment benefit replacement rate, unemployment rates, wages and vacancies. I consider that such a reform would make institutions converge at a level of flexibility that belongs to the range between the labor market institutions of the most flexible country and those of the most rigid country. Thus, I calibrate the model for any possible level of rigidity of the labor market between the one of the Home country (low rigidity) in the baseline model and the one of the Foreign country (high rigidity). This way, I can look at welfare consequences of a convergence of labor market institutions.

First, I look at the structural welfare effects, comparing welfare in each steady state. Second, I contrast the business cycle implications of the two convergence experiments. More precisely, I compute the welfare losses from business cycles around the initial and final steady states. Both analyses suggest that the welfare gains from labor market convergence are potentially important if made at a flexible level. Then, I look at the transition process. I find that the main results remain broadly unchanged. High welfare gains occur in the long run when the transition is made at a flexible level.

\subsection{Steady-state to steady-state analysis}

I calibrate the model so that labor markets are identical in both countries to conduct a welfare comparison with the baseline calibration. I investigate the range of possible labor market calibrations from the one of the Foreign country to the one of the Home country. Each case is compared to the baseline steady state both in terms of the welfare losses from fluctuations they imply (stabilization welfare gains/losses), and in terms of expected utility (structural welfare gains/losses). I look at aggregate and country-level welfare gains/losses. More precisely, let

$$
\begin{aligned}
\Omega_{t}^{M U} & =n u\left(C_{t}, U_{t}\right)+(1-n) u\left(C_{t}^{*}, U_{t}^{*}\right)+\beta \Omega_{t+1}^{M U} \\
\Omega_{t} & =u\left(C_{t}, U_{t}\right)+\beta \Omega_{t+1} \\
\Omega_{t}^{*} & =u\left(C_{t}^{*}, U_{t}^{*}\right)+\beta \Omega_{t+1}^{*}
\end{aligned}
$$

respectively denote the Monetary Union, Home and Foreign welfare measures. The two types of welfare gains/losses, structural and stabilization, are respectively defined as:

$$
\begin{aligned}
\Delta_{S t r}^{i} & =\frac{E_{t}\left(\Omega_{C}^{i}\right)-E_{t}\left(\Omega_{B}^{i}\right)}{E_{t}\left(C_{B}^{i}\right)} \\
\Delta_{S t a}^{i} & =\frac{E_{t}\left(\Omega_{C}^{i}\right)-\bar{\Omega}_{C}^{i}-\left(E_{t}\left(\Omega_{B}^{i}\right)-\bar{\Omega}_{B}\right)}{E_{t}\left(C_{B}^{i}\right)}
\end{aligned}
$$

for $i=\{M U, H, F\}$, where $E_{t}\left(C_{B}^{M U}\right)=n E_{t}\left(C_{B}\right)+(1-n) E_{t}\left(C_{B}^{*}\right)$. The subscripts $C$ and $B$ respectively stand for convergence calibration $(\mathrm{C})$ and baseline calibration (B). Structural 
welfare gains mean a higher expected utility. Stabilization welfare gains indicate lower secondorder fluctuations at the business cycle frequency. In this case, the expected average welfare becomes closer to its steady-state level. Complete results are reported in Figure 3 below. The parameter $x$ indicates how close to the baseline calibration of the Home country the convergence is made. More precisely, a value of $x=0$ means that the convergence is implemented at the baseline calibration of the Foreign country (the one with rigid labor markets) while a value of $x=1$ indicates that the convergence is implemented at the baseline calibration of the Home country (the flexible one). The higher $x$, the more flexible the labor market is at the final steadystate. Figure 3 is completed by Table 3 that shows structural and stabilization gains for specific levels of flexibility: for the convergence towards the most rigid labor market studied $(x=0)$, for a convergence towards the size-weighted average calibration $(x=0.41)$ and for a convergence towards the most flexible labor market studied $(x=1)$; and by Table 4 that shows steady-state values of important variables for those levels of $x$.

As indicated in Figure 3, the higher the value of $x$, the better the consequences in terms of structural welfare for the Home and the Foreign countries, and the Monetary Union as a whole. Furthermore, whatever the flexibility of the labor market at which the convergence is implemented, the Foreign country gains from the homogenization of the labor market while the Home country loses. The Foreign country gains in flexibility for any value of $x$ except 0 while the Home country loses in flexibility for any value of $x$ except 1 . An increase of flexibility in the labor market leads to a higher ability for firms to hire and for workers to find jobs, which leads the country to better face shocks. Therefore, the higher the flexibility (the higher $x$ ), the lower the unemployment rate and the higher per-capita consumption. As a consequence, structural gains are higher for the Foreign country and losses smaller for the Home country as $x$ increases.

Further, for a convergence at $x=0$, the Foreign country gains in terms of structural welfare while having the same labor market as in the baseline; and at $x=1$, the Home country loses welfare while it has the same labor market as in the baseline. Both results come from the fact that under the baseline calibration, workers in the Foreign country have a slightly higher wage as their bargaining power is higher. Therefore, they are net creditors in international bonds. But when the labor markets of both countries converge, wages become identical. Thus, the financial balances in both countries almost become null. This means that the Foreign family buys less bonds while the Home family buys more, reflecting changes in net wealth levels. As a consequence, for a convergence at $x=0$, the family in the Foreign country has more income, that is used to increase consumption compared to the baseline, leading to structural welfare gains. On the opposite, for $x=1$, the Home family lowers consumption to buy international bonds, which brings structural welfare losses.

Finally, the monetary union as a whole gains in terms of structural welfare for $x \in[0.27 ; 1]$. Thus, the union has structural welfare gains for a large portion of the range of convergence calibrations studied. A convergence towards the size-weighted average already brings substantial structural welfare gains, as large as $1.52 \%$ of permanent per-capita consumption. As demonstrated by 
Table 4, at the average level, the unemployment rate of the monetary union is lower than for the baseline and per-capita output and consumption are both larger. This comes from the fact that the Central Bank conducts a monetary policy that better fits the situation of both countries when they have identical labor markets.

Focusing on stabilization gains, a similar pattern emerges: the higher the flexibility, the higher the welfare gains. Furthermore, the gains are concave over $x$. As pinpointed in Table 2 and by the Impulse Response Functions in Appendix B, in the baseline, the volatility of unemployment is lower for the Home country than the Foreign one. This result comes from the lower unemployment in the flexible country, that brings a greater labor market tightness $\left(\theta_{t}\right)$. The per-capita consumption depends directly on the relative number of employed individuals (paid the country's wage) to unemployed individuals (earning the country's UI benefits). Therefore, the volatility of consumption - and of welfare - is smallest when the unemployment volatility is lowest, i.e. for $x=1$. However, unlike what occurs for the structural welfare analysis, the Foreign country experiences stabilization welfare losses for very low values of $x$ (less than 0.04). Indeed, the increase of the average unemployment level in the Monetary Union as a whole has negative stabilization welfare consequences. The Home country gains in term of stabilization welfare for the range of values $x \in[0.51 ; 1]$ and the monetary union obtains stabilization gains for $x \in[0.17 ; 1]$. The large range of values that bring stabilization gains for the Monetary Union as a whole shows again the benefit of an homogenization of labor markets in a monetary union, as the monetary authority can choose a monetary policy that is more effective in both countries.

Table 3: Welfare analysis

\begin{tabular}{|c|c|c|c|c|}
\hline & \multicolumn{4}{|c|}{ Structural welfare gains } \\
\hline & Monetary & Union & Home & Foreign \\
\hline Rigid & & -3.7961 & -12.5469 & 2.7291 \\
\hline Average & & 1.5186 & -7.4306 & 8.1915 \\
\hline \multirow[t]{3}{*}{ Flexible } & & 5.7860 & -3.3222 & 12.5776 \\
\hline & \multicolumn{4}{|c|}{ Stabilization welfare gains } \\
\hline & Monetary & Union & Home & Foreign \\
\hline Rigid & & -0.1838 & -0.3511 & -0.0582 \\
\hline Average & & 0.1352 & -0.0299 & 0.2589 \\
\hline Flexible & & 0.2381 & 0.0810 & 0.3558 \\
\hline
\end{tabular}

Results are expressed in percentage of permanent per-capita consumption of the baseline calibration.

The above analysis suffers from an important limitation: welfare numbers are computed in a static way, comparing steady state to steady state. However, if a reform fostering convergence on European labor markets was implemented, the path from heterogeneity to homogeneity may bring more complex welfare variations. The transition may generate short-term negative effects on consumption and other variables. So, even if convergence brings theoretical welfare gains when 
Figure 3: Steady-state welfare gains
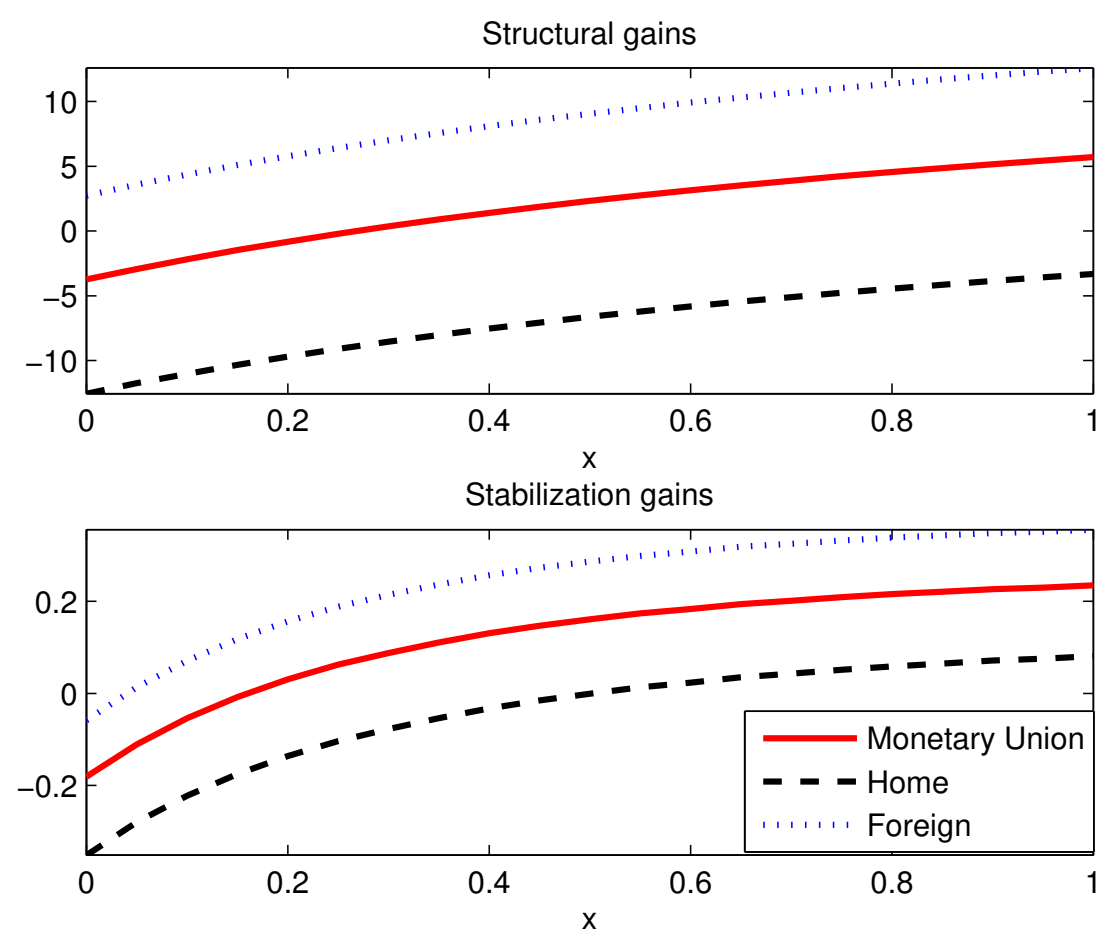

Results are expressed in percentage of permanent per-capita consumption of the baseline calibration.

Table 4: Steady-state levels of key variables

\begin{tabular}{|c|c|c|c|}
\hline & \multicolumn{3}{|c|}{ Output } \\
\hline & Monetary Union & Home & Foreign \\
\hline Baseline & 0.9702 & 0.9964 & 0.9520 \\
\hline Rigid & 0.9520 & 0.9520 & 0.9520 \\
\hline Average & 0.9751 & 0.9751 & 0.9751 \\
\hline \multirow[t]{3}{*}{ Flexible } & 0.9964 & 0.9964 & 0.9964 \\
\hline & \multicolumn{3}{|c|}{ Consumption } \\
\hline & Monetary Union & Home & Foreign \\
\hline Baseline & 0.6145 & 0.6395 & 0.5971 \\
\hline Rigid & 0.6033 & 0.6033 & 0.6033 \\
\hline Average & 0.6177 & 0.6177 & 0.6177 \\
\hline \multirow[t]{3}{*}{ Flexible } & 0.6305 & 0.6305 & 0.6305 \\
\hline & \multicolumn{3}{|c|}{ Unemployment rate } \\
\hline & Monetary Union & Home & Foreign \\
\hline Baseline & 9.4684 & 6.9948 & 11.1874 \\
\hline Rigid & 11.1874 & 11.1874 & 11.1874 \\
\hline Average & 9.0089 & 9.0089 & 9.0089 \\
\hline Flexible & 6.9948 & 6.9948 & 6.9948 \\
\hline
\end{tabular}

Results are expressed per-capita. Unemployment rates are indicated in percentages. 
comparing steady states, studying the transition process is essential in assessing the desirability of an homogenization of the labor market from the perspective of welfare.

\subsection{Transitional analysis}

To determine the consequences of a transition in terms of welfare, I calculate the Hicksianequivalent consumption change implied by the transition process over 500 periods - or equivalently 125 years. The Hicksian-equivalent change measures the percentage of permanent per-capita consumption $\xi_{T}$ that families would have to lose - or gain - to be indifferent between the situation where labor markets are heterogeneous and the one where a legislation modifies labor markets until they become homogeneous in the whole Euro Area, during $T$ periods:

$$
E_{0} \sum_{t=0}^{T} \beta^{t}\left[u\left(\left(1-\xi_{T}\right) C_{t}^{i}, U_{t}^{i}\right)\right]=\sum_{t=0}^{T} \beta^{t}\left[u\left(C_{0}^{i}, U_{0}^{i}\right)\right]
$$

I also report short-term variations of $\xi_{T}$, i.e. for small $T$, as short-term losses tend to arise in transition processes. I consider the short-term to last four years, as it is close to the length of most public-office terms. This way, I can look at the political feasibility of the reform. ${ }^{17}$ In this experiment, I use a perfect-foresight non-linear solution of the model. ${ }^{18}$

Even if a piece of legislation that requires a complete harmonization of labor market institutions in the Euro Area is implemented, it would not lead to an immediate convergence of all labor market parameters. Due to the influence of previous periods' values, variables cannot jump to their final steady-state values, but smoothly reach their final values. Therefore, I model the gradual convergence of the labor market variables according to the following process:

$$
\begin{aligned}
\Lambda_{t} & =\left(1-\rho_{\Lambda}\right) Z_{t}+\rho_{\Lambda} \Lambda_{t-1} \\
\log \left(\Upsilon_{t}\right) & =\Lambda_{t} \log \left(\bar{\Upsilon}_{I}\right)+\left(1-\Lambda_{t}\right) \log \left(\bar{\Upsilon}_{F}\right) \\
\log \left(\Upsilon_{t}^{*}\right) & =\Lambda_{t} \log \left(\bar{\Upsilon}_{I}^{*}\right)+\left(1-\Lambda_{t}\right) \log \left(\bar{\Upsilon}_{F}^{*}\right)
\end{aligned}
$$

for $\Upsilon=\left\{\rho^{x}, \chi, m, \sigma, \kappa, h, \tau^{W}, F\right\}$ and where $\bar{\Upsilon}_{I}$ and $\bar{\Upsilon}_{F}$ are respectively the initial and final steady-state levels of each converging variable. At the end of period $0, Z_{t}$ switches from 1 to 0 , which triggers a convergence process for the above variables. The speed of the convergence is governed by $\rho_{\Lambda}$, the persistence of $\Lambda_{t}$. The job-hiring rates, the job-filling rates and the total separation rates remain defined by equilibrium conditions and therefore smoothly move to their final steady states as the other variables adjust following the homogenization process.

Figure 4 shows results of the transition process for $\rho_{\Lambda}=0.9$ for the whole range of convergence

\footnotetext{
${ }^{17}$ The division between short and long term to assess governments' interest in implementing a reform is also used in Cacciatore and Fiori (2016) although they choose a length of three years.

${ }^{18}$ The algorithm is taken from Dynare and based on a Newton-type algorithm that solves a set of non-linear equations at each period using the special structure of the Jacobian matrix. See Juillard (1996) for details about the algorithm.
} 
calibrations from $x=0$ to $x=1 .^{19}$ This speed of convergence seems quite realistic as it implies that more than half of the convergence takes place in seven periods and more than $80 \%$ in 16 periods. The transition analysis gives results that are consistent with the steady-state to steadystate study. The higher the after-convergence flexibility of the labor market, the higher the welfare gains - or the lower the losses. Furthermore, as expected, the Foreign country benefits the most from the convergence process. However, it slightly loses welfare in the short run for a low value of $x$ (up to $0.39 \%$ of permanent consumption for $x=0$ ). On the opposite, the Home country experiences only very small welfare losses on the short run for a convergence at a high value of $x$.

Whatever the level of convergence, the homogenization of the labor markets was not anticipated by agents. Therefore, in period 1 - and only in period 1 - equilibrium conditions do not hold. Individuals in the Home country understand that the convergence will lead to a higher wage as the bargaining power of workers and their outside option will increase. Therefore, they bargain a higher wage in period 1 . This increase of wages in the Home country has a positive effect on consumption and unemployment during the first few periods. These short-term gains decrease welfare losses for the Home country. However, they are too low to overturn the welfare losses that come from a loss of flexibility whatever the after-convergence labor market flexibility. The opposite mechanism takes place in the Foreign country during the first few periods. The wage decreases strongly as the bargaining power of workers and their outside option decrease, which has a negative effect on consumption and unemployment. Therefore, welfare gains are lower than for the steady-state to steady-state comparison. It even leads to a small decrease of welfare on the short term for a convergence at a high rigidity level $(x \in[0,0.2])$. Indeed, the convergence brings too low gains in this case as the increase in labor market flexibility is very small.

However, the increase of wages in the Home country leads to an increase of prices while in the Foreign country the decrease of wages causes a decrease of prices. As a consequence, the terms of trade fall. Therefore, the demand for the varieties of goods produced in the Home country decreases. Firms respond by hiring less workers. As unemployment increases, consumption decreases and so does welfare, explaining why this short-term effect vanishes after the very few periods. The terms of trade come back to a more usual level thanks to a fall (increase) of wages in the Home (Foreign) country as the labor market gets looser (tighter). Then, only the longterm effects of the labor market reform are felt. Overall, in the long run, the welfare results in the full transition path analysis are close to those obtained in the steady-state to steady-state comparison, the variations being only of lower magnitude.

As a weighted average, the Monetary Union as a whole gains welfare when the convergence is made at a flexible level but loses when the convergence is implemented at a rigid level as for the steady-state to steady-state analysis. Indeed, a higher flexibility means that hires are higher, therefore unemployed individuals find more easily a job. As a consequence, it leads to a lower unemployment level and a higher consumption. In the short run, welfare gains occur from

\footnotetext{
${ }^{19}$ The precise changes of welfare over time are indicated for $x=0, x=0.41$ and $x=1$ in Appendix C.
} 
$x=0.54$ but in the long run, gains appear from $x=0.36$. Thus, even from a short-term political view, the reform is beneficial for the Foreign country and for the Monetary Union for a wide range of calibrations.

Table 5 shows results of the transition analysis for a convergence towards specific values of $x$, and for different speeds of convergence for comparison purposes. As for the steady-state to steadystate analysis, I look at a convergence towards a rigid calibration $x=0$, the size-weighted average calibration $x=0.41$ and a flexible calibration $x=1$. Besides $\rho_{\Lambda}=0.9$, I display results for a slow transition $\rho_{\Lambda}=0.99$ and a quick transition $\rho_{\Lambda}=0.5$. The table reveals that the speed of convergence has no qualitative impacts on the results. However, it plays a role quantitatively speaking. For a convergence at $x=0$ or at $x=0.41$, the quicker the transition (the lower $\rho_{\Lambda}$ ), the higher the welfare losses for the Home country. This is due to the fact that increasing the speed of transition means that the Home country loses flexibility quicker. As welfare losses are discounted over time, a stronger decrease of the flexibility of the labor market during the first periods leads to a greater fall of welfare. On the contrary, for a convergence at $x=0.41$ or $x=1$, the Foreign country gains more in terms of welfare when the transition is quicker as the flexibilization of its labor market is more rapid. When the convergence is made at a rigid level, the long term welfare effect for the Foreign country is very low as changes concerning its labor market on the long run are very small (or null for $x=0$ ). Therefore, changing the speed of convergence has very little impact in terms of welfare. The same happens for the Home country with a convergence at a flexible level. Since the long-term impact on welfare is very small, modifying the speed of convergence has little effect.

The Monetary Union as a whole loses more in terms of welfare in the rigid case when the transition is quicker. Indeed, an increase of the speed of convergence has little effect on the Foreign country but raises losses for the Home country. The opposite mechanism occurs for a convergence towards the flexible level. Increasing the speed of transition leads to higher welfare gains for the Foreign country and little changes for the Home country. Therefore, welfare gains are higher for the Monetary Union when the speed of convergence is higher. At the average level, the speed of convergence has very little impact for the Monetary Union. Whatever $\rho_{\Lambda}$, the Monetary Union suffers from small losses on the short run and small gains on the long run.

\section{Conclusion}

In this paper, I study the consequences of labor market convergence in the Euro Area. I use a DSGE model with two countries in a monetary union with Rotemberg adjustment costs, trade in consumption and investment goods, and search and matching frictions with firing costs on the labor market. I look at the whole range of possible convergences between the actual calibration of the Home country (the flexible one) and of the Foreign country (the rigid one). I find that the after-convergence labor market flexibility level is of paramount importance for the outcome. The

higher the flexibility the higher the welfare gains or the lower the losses. Comparing steady-state 
Figure 4: Welfare gains after a transition

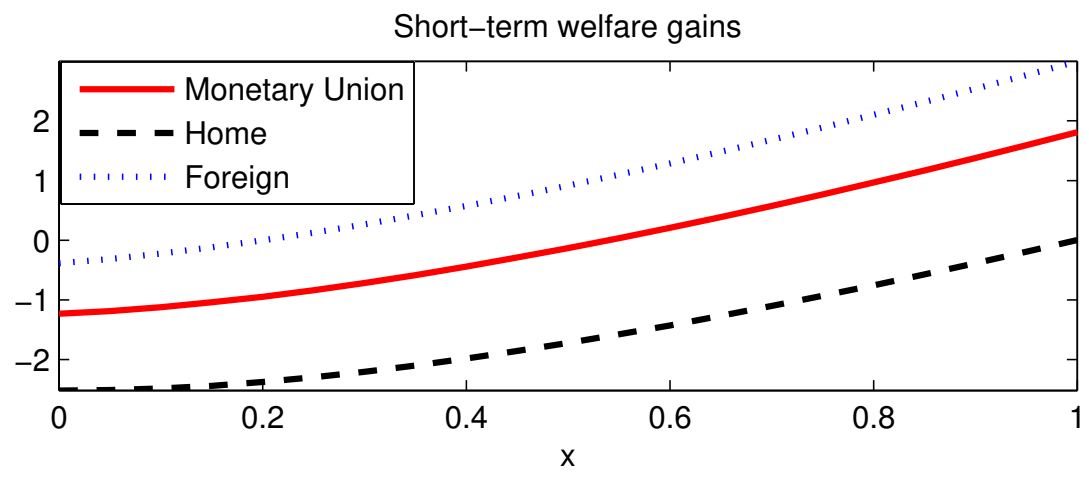

Total welfare gains

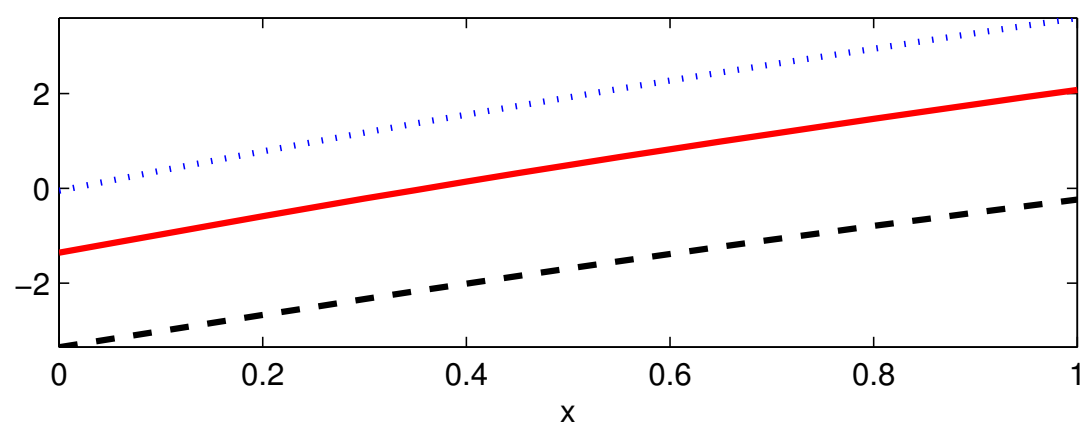

Table 5: Welfare gains for different speeds of convergence

\begin{tabular}{|c|c|c|c|c|c|c|}
\hline \multirow[b]{3}{*}{$\rho_{\Lambda}$} & \multicolumn{6}{|c|}{ Monetary Union } \\
\hline & \multicolumn{2}{|c|}{ Rigid } & \multicolumn{2}{|c|}{ Average } & \multicolumn{2}{|c|}{ Flexible } \\
\hline & $\mathrm{ST}$ & Total & $\mathrm{ST}$ & Total & ST & Total \\
\hline 0.99 & -0.6085 & -0.4983 & -0.4361 & 0.2336 & 1.0614 & 1.5083 \\
\hline 0.90 & -1.2325 & -1.3592 & -0.4126 & 0.1773 & 1.8091 & 2.0784 \\
\hline \multirow[t]{3}{*}{0.50} & -1.6587 & -1.5750 & -0.5119 & 0.1331 & 1.9419 & 2.1359 \\
\hline & \multicolumn{6}{|c|}{ Home } \\
\hline & \multicolumn{2}{|c|}{ Rigid } & \multicolumn{2}{|c|}{ Average } & \multicolumn{2}{|c|}{ Flexible } \\
\hline$\rho_{\Lambda}$ & $\mathrm{ST}$ & Total & $\mathrm{ST}$ & Total & ST & Total \\
\hline 0.99 & -1.2548 & -1.6567 & -1.2675 & -1.1845 & -0.0334 & -0.2690 \\
\hline 0.90 & -2.5172 & -3.3496 & -1.9595 & -1.9773 & 0.0021 & -0.2369 \\
\hline \multirow[t]{3}{*}{0.50} & -3.4936 & -3.8427 & -2.4478 & -2.2087 & -0.0538 & -0.2703 \\
\hline & \multicolumn{6}{|c|}{ Foreign } \\
\hline & \multicolumn{2}{|c|}{ Rigid } & \multicolumn{2}{|c|}{ Average } & \multicolumn{2}{|c|}{ Flexible } \\
\hline$\rho_{\Lambda}$ & $\mathrm{ST}$ & Total & $\mathbf{S T}$ & Total & ST & Total \\
\hline 0.99 & -0.1814 & 0.2657 & 0.1133 & 1.1676 & 1.7842 & 2.6771 \\
\hline 0.90 & -0.3850 & -0.0508 & 0.6073 & 1.5920 & 2.9992 & 3.5971 \\
\hline 0.50 & -0.4509 & -0.0860 & 0.7613 & 1.6694 & 3.2533 & 3.7134 \\
\hline
\end{tabular}

Results are given in percentage of permanent consumption. A positive number indicates a gain from a convergence of labor markets. ST stands for short-term welfare gains. 
outcomes, an homogeneous labor market brings structural and stabilization welfare gains for the Foreign country as it gains in flexibility. On the contrary, the Home country experiences structural welfare losses for any convergence calibration as it gains in rigidity. However, it experiences stabilization gains for a large range of calibrations. This is due to a more effective monetary policy when countries have more homogeneous labor markets. Furthermore, the Monetary Union experiences structural and stabilization welfare gains for a large fraction of the range of calibrations studied. Both results are indicative of the positive welfare impact of labor market convergence. The study of the full transition process shows qualitatively similar results, but quantitatively, welfare variations are smaller. A short-term mechanism involving the bargaining of wages at period 1 has negative effects on the Foreign country but positive effects on the Home country. This means that the Foreign country obtains lower welfare gains and may even lose welfare for a low after-convergence level of flexibility while the Home country experiences lower welfare losses. As a consequence, long-term welfare gains (losses) are also lower for the Foreign (Home) country. Furthermore, a smaller range of calibrations brings welfare gains for the Monetary Union whether in the short or in the long run. Overall, those results suggest that a convergence of the labor markets should be carefully implemented to be beneficial at least for the Foreign country and the Monetary Union as a whole both in the short term and in the long term.

\section{References}

Abbritti, M. and A. Mueller (2013). "Asymmetric labor market institutions in the EMU and volatility of inflation of inflation and unemployment differentials". Journal of Money, Credit and Banking 45(6), 1165-1186.

Adjemian, S., H. Bastani, M. Juillard, F. Karamé, J. Maih, F. Mihoubi, G. Perendia, J. Pfeifer, M. Ratto, and S. Villemot (2011). "Dynare: Reference manual, version 4". Dynare Working Papers 1. CEPREMAP.

Albertini, J. and X. Fairise (2013). "Search frictions, real wages rigidities and the optimal design of unemployment insurance". Journal of Economic Dynamics and Control 37, 1796-1813.

Andersen, T. and M. Seneca (2010). "Labour market asymmetries in a monetary union". Open Economies Review 21(4), 483-514.

Blanchard, O. and F. Giavazzi (2003). "Macroeconimic effects of regulation and deregulation in goods and labor markets". The Quarterly Journal of Economics 118(3), 879-907.

Blanchard, O. and J. Wolfers (2000). "The Role of shocks and institutions in the rise of european unemployment: The aggregate evidence". The Economic Journal 110(462), C1-C33. Conference Papers.

Born, B. and J. Pfeifer (2016). "The New Keynesian wage Phillips curve: Calvo vs. Rotemberg". Working Paper 51.

Brückner, M. and E. Pappa (2012). "Fiscal expansions, unemployment, and labor force participation: Theory and evidence". International Economic Review 53(4), 1205-1228. 
Cacciatore, M., R. Duval, G. Fiori, and F. Ghironi (2016). "Market reforms in the time of imbalance". Journal of Economic Dynamics and Control 72, 69-93.

Cacciatore, M. and G. Fiori (2016). "The Macroeconomic effects of goods and labor markets deregulation". Review of Economic Dynamics 20, 1-24.

Dellas, H. and G. Tavlas (2005). "Wage rigidity and monetary union". The Economic Journal 115, 907-927.

Diamond, P. (1982). "Aggregate demand management in search equilibrium". Journal of Political Economy 90(5), 881-894.

Eggertsson, G., A. Ferrero, and A. Raffo (2014). "Can structural reforms help Europe". Journal of Monetary Economics 61, 2-22.

Esser, I., T. Ferrarini, K. Nelson, J. Palme, and O. Sjöberg (2013). "Unemployment benefits in EU member states". Employment Social Affairs and Inclusion. European Commission.

Gomes, S., P. Jacquinot, M. Mohr, and M. Pisani (2013). "Structural reforms and macroeconomic performance in the Euro Area countries: a model based assessment". International Finance 16(1), 23-44.

Hobijn, B. and A. Sahin (2007). "Job-finding and separation rates in the OECD". Federal Reserve Bank of New York Staff Reports. No. 298.

Ireland, P. (2001). "Sticky-price models of the business cycle: Specification and stability". Journal of Monetary Economics 47(1), 3-18.

Juillard, M. (1996). "Dynare: A program for the resolution and simulation of dynamic models with forward variables through the use of a relaxation algorithm". CEPREMAP WP 424.

Keen, B. and Y. Wang (2007). "What is a realistic value for price adjustment costs in New Keynesian models?". Applied Economics Letters 14(11), 789-793.

Kontogiannis, N. (2015). "Optimal monetary policy in a currency union with labour market heterogeneity". INFER Working Paper series 2015.

Ljunqvist, L. and T. Sargent (2008). "Two questions about European unemployment". Econometrica $76(1), 1-29$.

Mayer, E., S. Moyen, and N. Stähler (2010). "Government expenditures and unemployment: A DSGE perspective". Bundesbank Series 1 Discussion. Paper 18/2010.

McKinnon, R. (1963). "Optimum currency areas". American Economic Review 53, 717-724.

Merz, M. (1995). "Search in the labor market and the real business cycle". Journal of Monetary Economics 36(2), 269-300.

Mortensen, D. (1982). "Property rights and efficiency in mating, racing and related games". American Economic Review 72(5), 968-979.

Mundell, R. (1961). "A Theory of optimum currency area". American Economic Review 51(4), $657-665$.

Nardo, M. and F. Rossetti (2013). "Flexicurity in Europe". European Commission. DirectorateGeneral for Employment, Social Affairs and Inclusion. 
Nickell, S. (1997). "Unemployment and labor market rigidities: Europe versus North America". Journal of Economic Perspectives 11(3), 55-74.

Obstfeld, M. and K. Rogoff (2005). "Global current account imbalances and exchange rate adjustments". Brookings Papers on Economic Activity 2005(1), 67-123.

Pappa, E. and V. Vassilatos (2007). "The Unbearable tightness of being in a monetary union: Fiscal restrictions and regional stability". European Economic Review 51 (6), 1492-1513.

Petrongolo, B. and C. Pissarides (2001). "Looking into the black box: a survey of the matching function". Journal of Economic Litterature 39(2), 390-431.

Pissarides, C. (1979). "Job matchings with state employment agencies and random search". Economic Journal 89(356), 818-833.

Rotemberg, J. (1982). "Sticky prices in the United States". Journal of Political Economy 90, $1187-1211$.

Schmitt-Grohé, S. and M. Uribe (2003). "Closing small open economy models". Journal of International Economics 61(1), 163-185.

Thomas, C. (2006). "Firing costs, labor market search and the business cycle". London School of Economics, mimeo.

Trabandt, M. and H. Uhlig (2013). "How do Laffer curves differ across countries?". In A. Alesina and F. Giavazzi (Eds.), Fiscal Policy After the Financial Crisis, pp. 211-244. Chicago: Chicago Press.

Zanetti, F. (2011). "Labor market institutions and aggregate fluctuations in a search and matching model". European Economic Review 55(2011), 644-658. 


\section{A Methodology to separate countries into two groups}

The goal is to separate countries of the Euro Area into two groups according to the relative flexibility of their labor markets. Therefore, I make two clusters using the Employment Protection database of the OECD. I use the level 3 of the indicators that includes 6 categories: procedurial inconveniance, notice and severance pay for no-fault individual dismissal, difficulty of dismissal, collective dismissals, fixed-term contract protection, and temporary work agency employment. Data for this new methodology are available for the years 2008 to 2013. Thus, I use an average value over this period for each country I am interested in for the study (Austria, Belgium, Finland, France, Germany, Greece, Ireland, Italy, Luxembourg, the Netherlands, Portugal and Spain).

Then, I use the function k-means in MATLAB requesting to get two clusters. I chose the classification that performs the best in terms of the sum of distances, that is: Austria, Finland, Germany, Ireland and the Netherlands for the flexible group and Belgium, France, Greece, Italy, Luxembourg, Portugal and Spain for the rigid one.

\section{B Impulse Response Functions}

Responses to local technology shocks. Figure 5 depicts local responses of key variables to the positive technology shocks in the core (solid line) and in the periphery (dashed line) ${ }^{20}$ Notice that the cross-country correlation of shocks has been set to zero to disentangle the effects of a purely asymmetric shock. As usual in RBC models, the productivity shock raises wages and rental rates in period 2, but less than the rise in productivity, which makes marginal production costs fall. Firms can produce more with the same amount of inputs and expand production, raising the capital stock, vacancies and then hires. Local prices drop, therefore raising local and foreign demand for local varieties of goods, which is consistent with the increase in output. The family experiences a rise in its income through capital and labor, and uses it to smoothly rise its level of consumption. This consumption smoothing is achieved by raising investment in capital. Movements in quantities are greater in the periphery: the higher steady-state level of unemployment leads to a looser labor market in the periphery $\left(\theta_{t}^{*}<\theta_{t}\right)$, which makes vacancies easier to fill and therefore amplifies movements in employment after productivity shocks. As a consequence, the response of most macroeconomic aggregates (consumption in particular) are also amplified.

Responses to an external technology shock. Figure 6 presents the response of key variables to a technology shock hitting the other country of the Euro Area. In other words Graph 6 shows the international transmission of productivity shocks. Here too, the shock is a purely asymmetric shock. An external productivity shock raises the relative price of the production good, which lowers the purchasing power of households and raises the price of production factors. As such, it increases the marginal production cost, leading inflation to jump. This raises the

\footnotetext{
${ }^{20}$ Results are given in percent deviation from the steady-state level.
} 
real interest rate, undermining consumption and causing an increase of the cost of capital and in fine a fall in investment. As the latter decreases, the stock of capital diminishes, forcing firms to hire more workers to maintain production. Therefore employment, vacancies (in the Foreign country) and wages increase during the first periods. However, the family knows an increase of domestic prices will have negative consequences. Therefore, they decrease their consumption. As a consequence, output decreases which leads vacancies to fall and unemployment to go back to its steady-state level. As the effects of the shock fade, consumption ends up increasing, even exceeding its steady-state level in the Home country. As the Foreign country is larger in size, when a positive technology shock occurs there, the interest rate increases more. Thus, the Home country suffers from a larger fall in investment, capital and output. However, unlike what occurs in the Foreign country, in case of an external shock, the unemployment rate does not exceed its steady-state level in the Home country due to its tighter labor market. 
Figure 5: Impulse response functions after a local technology shock
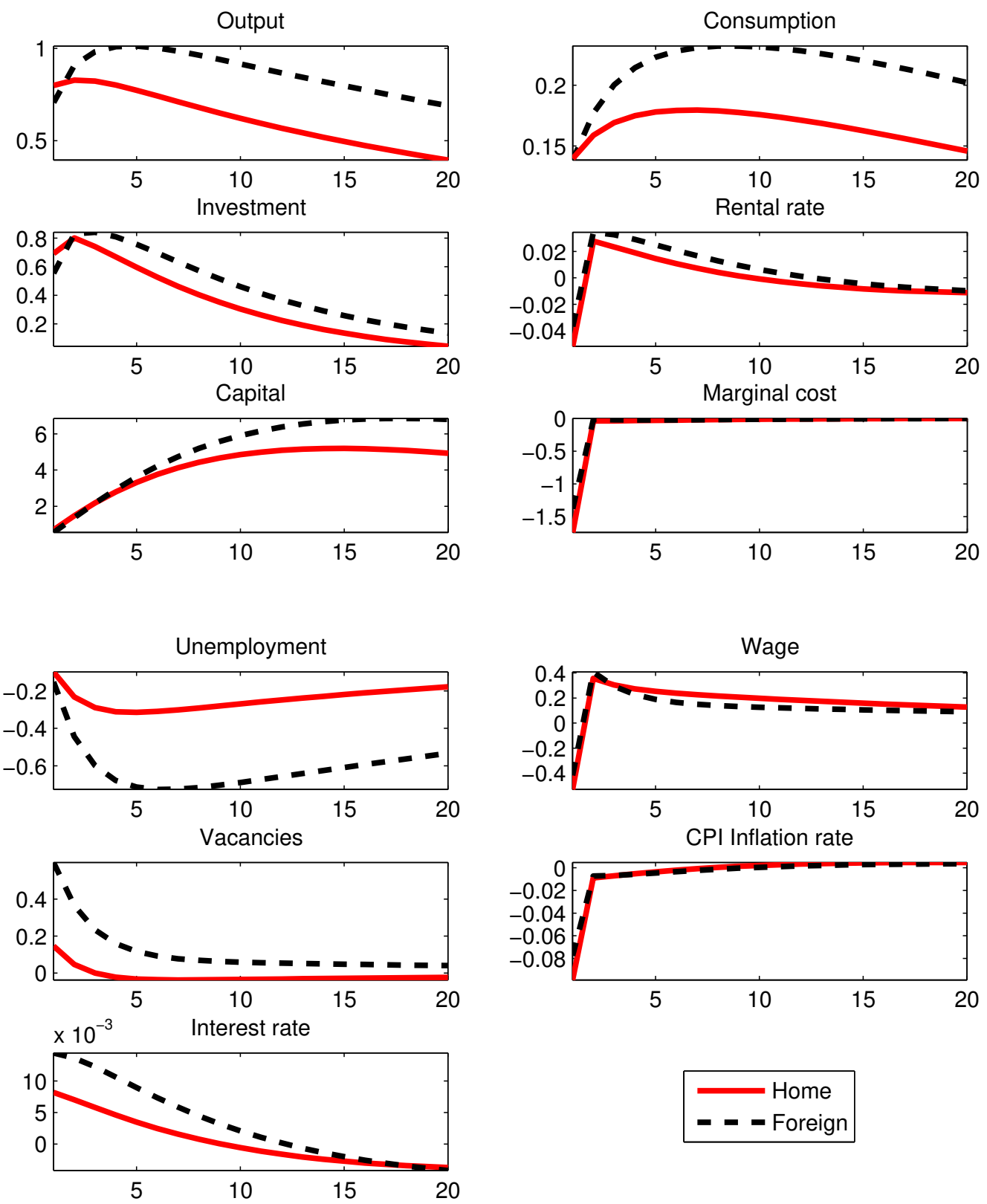
Figure 6: Impulse response functions after an external technology shock
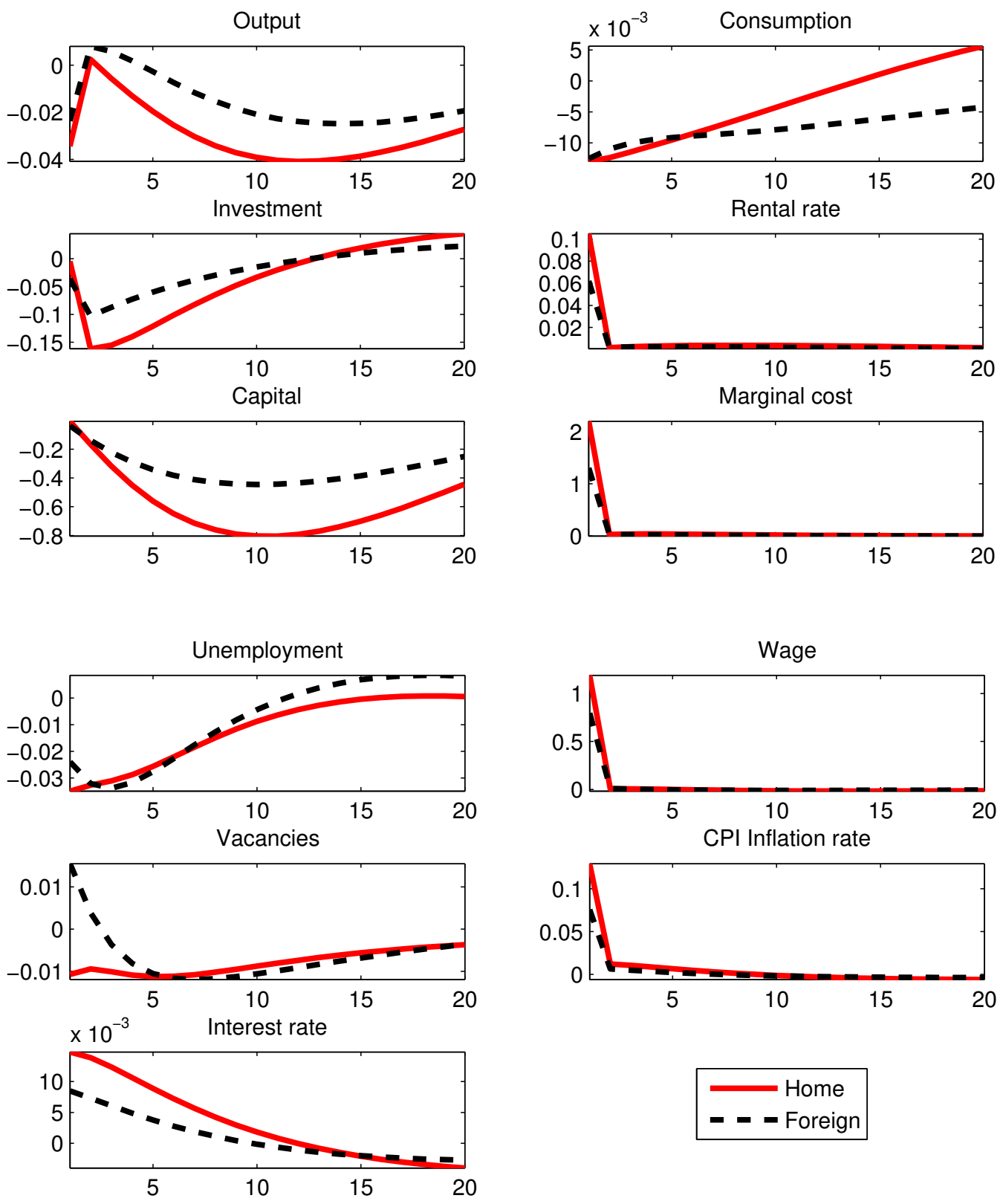

Home

- - Foreign 
C Cumulative transition welfare gains and losses
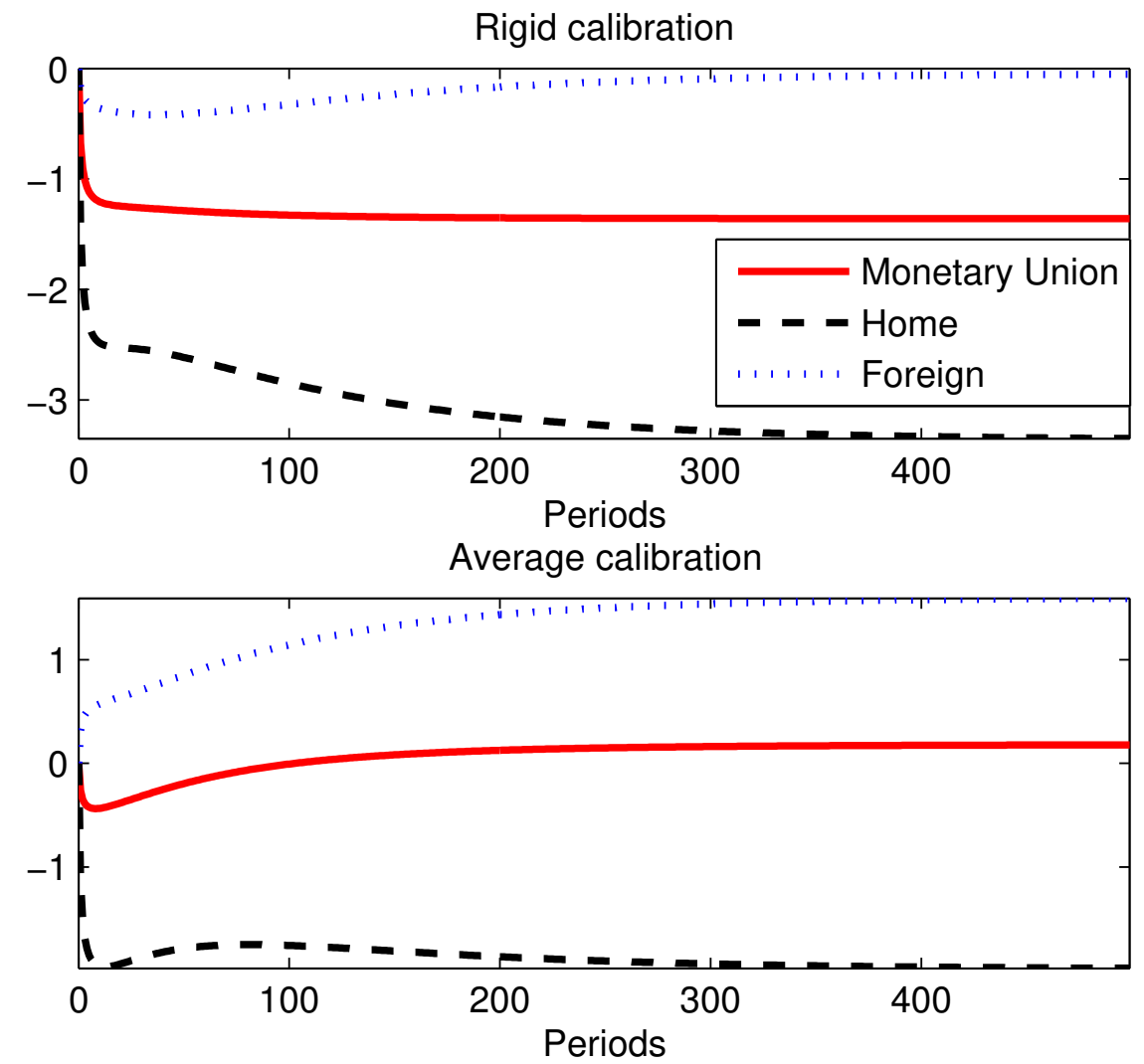

Flexible calibration

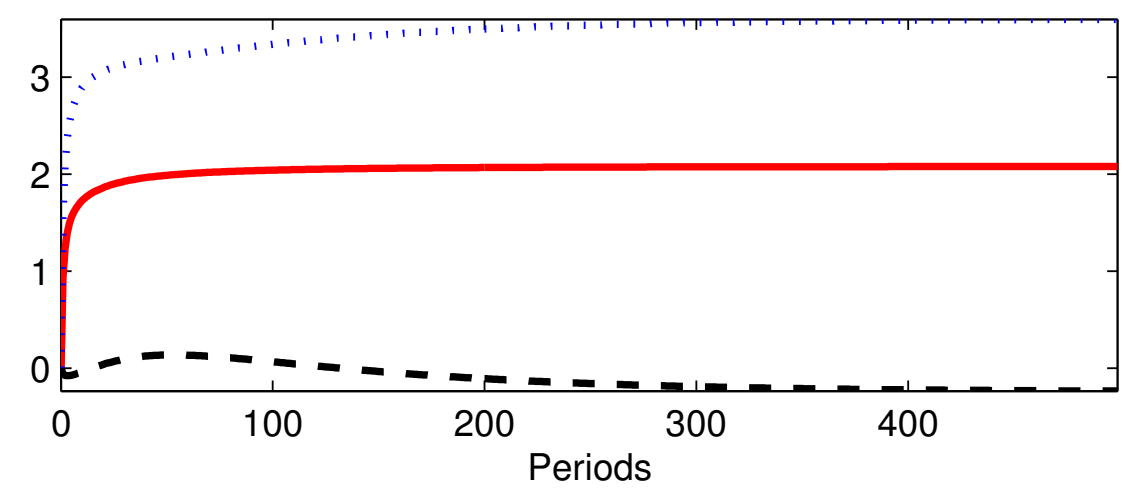

